\title{
Modelling spatio-temporal patterns of fish community size structure across the northern Mediterranean Sea: an analysis combining MEDITS survey data with environmental and anthropogenic drivers
}

\author{
Isabella Bitetto ${ }^{1}$, Giovanni Romagnoni ${ }^{1,2}$, Angeliki Adamidou ${ }^{3}$, Gregoire Certain ${ }^{4}$, \\ Manfredi Di Lorenzo ${ }^{5}$, Marilena Donnaloia ${ }^{1}$, Giuseppe Lembo ${ }^{1}$, Porzia Maiorano ${ }^{6}$, \\ Giacomo Milisenda ${ }^{7}$, Claudia Musumeci ${ }^{8}$, Francesc Ordines ${ }^{9}$, Paola Pesci ${ }^{10}$, \\ Panagiota Peristeraki ${ }^{11}$, Ana Pesic ${ }^{12}$, Paolo Sartor ${ }^{8}$, Maria Teresa Spedicato ${ }^{1}$ \\ ${ }^{1}$ COISPA Tecnologia \& Ricerca, Bari, Italy. \\ (IB) (Corresponding author) E-mail: bitetto@ coispa.it. ORCID iD: https://orcid.org/0000-0002-8497-1642 \\ (GR) E-mail: romagnoni@coispa.eu. ORCID iD: https://orcid.org/0000-0002-2208-3017 \\ (MD) E-mail: donnaloia@ coispa.eu. ORCID iD: https://orcid.org/0000-0001-6707-0503 \\ (GL) E-mail: lembo@coispa.it. ORCID iD: https://orcid.org/0000-0002-9899-6189 \\ (MTS) E-mail: spedicato@ coispa.it. ORCID iD: https://orcid.org/0000-0001-9939-9426 \\ ${ }^{2}$ Centre for Ecological and Evolutionary Synthesis (CEES), Dept. of Biosciences, University of Oslo, Norway. \\ ${ }^{3}$ FRI, Kavala, Greece. \\ (AA) E-mail: adamidou@inale.gr. ORCID iD: https://orcid.org/0000-0002-9958-3407 \\ ${ }^{4}$ UMR MARBEC IFREMER-LHM, Sète, France. \\ (GC) E-mail: gregoire.certain@ifremer.fr. ORCID iD: https://orcid.org/0000-0002-5242-5268 \\ ${ }_{5}^{5}$ Institute for Biological Resources and Marine Biotechnologies, National Research Council (IRBIM-CNR), \\ Via Luigi Vaccara 61, 91026 Mazara del Vallo, TP, Italy. \\ (MD) E-mail: manfredi.dilorenzo@cnr.it. ORCID iD: https://orcid.org/0000-0003-3786-5772 \\ ${ }^{6}$ Dipartimento di Biologia, Bari University of Aldo Moro, Italy. \\ (PM) E-mail: porzia.maiorano@ uniba.it. ORCID iD: https://orcid.org/0000-0001-5737-3025 \\ ${ }^{7}$ SZN (Stazione zoologica Anton Dohrn), Dipartimento di ecologia marina integrata, Viale Cristoforo Colombo, 90142 \\ Palermo, Italy. \\ (GM) E-mail: giacomo.milisenda@gmail.com. ORCID iD: https://orcid.org/0000-0003-1334-9749 \\ ${ }^{8}$ CIBM, Livorno, Italy. \\ (CM) E-mail: musumeci@cibm.it. ORCID iD: https://orcid.org/0000-0001-9778-6254 \\ (PS) E-mail: sartor@cibm.it. ORCID iD: https://orcid.org/0000-0001-7239-8255 \\ ${ }^{9}$ Instituto Español de Oceanografía, Centre Oceanogràfic de les Balears, Palma, 07015 Illes Balears, Spain. \\ (FO) E-mail: xisco.ordinas@ieo.es. ORCID iD: https://orcid.org/0000-0002-2456-2214 \\ ${ }^{10}$ Department of Life and Environmental Sciences, University of Cagliari, via T. Fiorelli 1, 09126 Cagliari, Italy. \\ (PP) E-mail: ppesci@unica.it. ORCID iD: https://orcid.org/0000-0002-9066-8076 \\ ${ }^{11}$ Hellenic Center of Marine Research, Crete, Greece. \\ (PP) E-mail: notap@ @cmr.gr. ORCID iD: https://orcid.org/0000-0002-8608-078X \\ 12 University of Montenegro - Institute of Marine Biology, Kotor, Montenegro. \\ (AP) E-mail: pesica@ucg.ac.me. ORCID iD: https://orcid.org/0000-0002-8669-6744
}

\begin{abstract}
Summary: The state of marine systems subject to natural or anthropogenic impacts can be generally summarized by suites of ecological indicators carefully selected to avoid redundancy. Length-based indicators capture the status of fish community structure, fulfilling the Marine Strategy Framework Directive (MSFD) requirement for Descriptor 3 (status of commercial fish species). Although the MSFD recommends the development of regional indicators, a comparison among alternative length-based indicators is so far missing for the Mediterranean Sea. Using principal component analysis and dynamic factor analysis, we identified the most effective subset of length-based indicators, whether or not based on maximum length. Indicator trends and time series of fishing effort and environmental variables are also compared in order to highlight the individual and combined capability of indicators to track system changes across geographical sub-areas. Two indicators, typical length and mean maximum length, constitute the smallest set of non-redundant indicators, capturing together $87.45 \%$ of variability. Only in combination can these indicators disentangle changes in the fish community composition from modifications of size structure. Our study supports the inclusion of typical length among the regional MSFD Descriptor 3 indicators for the Mediterranean Sea. Finally, we show dissimilarity between the western and eastern-central Mediterranean, suggesting that there are sub-regional differences in stressors and community responses.
\end{abstract}

Keywords: demersal fish community; size structure indicators; geographical sub-area; Marine Strategy Framework Directive; dynamic factor analysis; redundancy analysis. 


\begin{abstract}
Modelado de patrones espacio-temporales de la estructura de tallas de la comunidad de peces a través del norte del mar Mediterráneo: un análisis combinando datos de campañas MEDITS y factores ambientales y antropogénicos
\end{abstract}

\begin{abstract}
Resumen: Generalmente, el estado de los sistemas marinos sujetos a impactos naturales o antropogénicos puede ser resumido mediante un conjunto de indicadores ecológicos, cuidadosamente seleccionados para evitar la redundancia. Los indicadores basados en la talla reflejan el estado de la estructura de la comunidad de peces, cumpliendo el requisito de la Directiva Marco de la Estrategia Marina (MSFD) para el Descriptor 3 (estado de las especies de peces comerciales). Si bien MSFD recomienda el desarrollo de indicadores regionales, en el Mar Mediterráneo no se ha hecho hasta ahora una comparación entre los distintos indicadores disponibles basados en la talla. Mediante el análisis de componentes principales y el análisis de factores dinámicos, identificamos el subconjunto más eficaz de indicadores basados en la talla, estén o no basados en la talla máxima. Las tendencias de los indicadores y las series temporales del esfuerzo de pesca y las variables ambientales también son comparadas para resaltar la capacidad individual y combinada de los indicadores para detectar los cambios del sistema a través de las subáreas geográficas. Dos indicadores, Longitud Típica (TyL) y Longitud Máxima Media (MML), constituyen el conjunto más pequeño de indicadores no redundantes, captando juntos el $87.45 \%$ de variabilidad. Solo si se combinan, estos indicadores pueden discernir entre los cambios en la composición de la comunidad de peces y las modificaciones de la estructura de tallas. Nuestro estudio respalda la inclusión de TyL entre los indicadores regionales del descriptor 3 de MSFD para el mar Mediterráneo. Finalmente, mostramos diferencias entre el Mediterráneo occidental y el Mediterráneo centraloriental que sugieren diferencias subregionales en cuanto a factores impactantes y las respuestas de la comunidad.
\end{abstract}

Palabras clave: Comunidad de peces demersales; indicadores de estructura de tallas; subárea geográfica; Directiva marco de estrategia marina; análisis dinámico de factores; análisis de redundancia.

Citation/Cómo citar este artículo: Bitetto I., Romagnoni G., Adamidou A., Certain G., Di Lorenzo M., Donnaloia M., Lembo G., Maiorano P., Milisenda G., Musumeci C., Ordines F., Pesci P., Peristeraki P., Pesic A., Sartor P., Spedicato M.T. 2019. Modelling spatio-temporal patterns of fish community size structure across the northern Mediterranean Sea: an analysis combining MEDITS survey data with environmental and anthropogenic drivers. Sci. Mar. 83S1: 141-151. https:// doi.org/10.3989/scimar.05015.06A

Editor: G. Tserpes.

Received: July 13, 2019. Accepted: November 15, 2019. Published: December 12, 2019.

Copyright: ( 2019 CSIC. This is an open-access article distributed under the terms of the Creative Commons Attribution 4.0 International (CC BY 4.0) License.

\section{INTRODUCTION}

Operational ecological indicators are generally used for summarizing the status of marine communities and ecosystems in a comprehensive and accessible way (Cury and Christensen 2005, Shin and Shannon 2010). Indicators of anthropogenic pressure are useful for monitoring the impact of fishing on target species, communities (Greenstreet et al. 2012b) and ecosystems (e.g. Shin and Shannon 2010), thus helping to assess the effectiveness of management measures (e.g. Fulton et al. 2005, Houle et al. 2012). Ecological and impact indicators are crucial in the design of multiannual management plans, which, according to the Common Fishery Policy (EU Reg. 1380/2013), should consider ecosystem descriptors in addition to fishing mortality targets at stock level.

Indicators of fish community size structure can reveal the fishing effects caused by removing certain sizes and altering the abundance of different-sized species. Given their ability to summarize such complex dynamics, indicators of fish community size structure are increasingly used by national and transnational legislation, such as the European Marine Strategy Framework Directive (MSFD), which seeks to achieve Good Environmental Status (GES) by 2020 for all European seas (European Commission 2010).

Because no single indicator can capture the diversity of dynamics and processes within a system, suites of indicators are indeed required (Greenstreet et al. 2012a), though the selection of indicators to retain should be carefully considered: indicators included should be sensitive to specific impacts (Houle et al. 2012) or be unambiguous to monitor single species, communities or ecosystems (Rochet and Trenkel 2003, Shin and Shannon 2010). The suite of indicators should be based on criteria such as availability and accessibility of data, conceptual basis, ability to track different dynamics and processes, responsiveness, communicability and relevance to management (Rochet et al. 2010, Shin and Shannon 2010). The selected suite should also avoid redundancy (Methratta and Link 2006, Greenstreet et al. 2012a) and ensure applicability across different geographical areas (Shin et al. 2018).

Several studies have assessed existing indicators to identify suites that best capture the diversity of impacts and dynamics for fish communities or for whole ecosystems (Shin et al. 2018). Most studies have focused on North Atlantic fisheries (Methratta and Link 2006, Greenstreet et al. 2012a) or compared multiple systems (e.g. Shin and Shannon 2010), while only a few have assessed the situation for the Mediterranean fish communities (Rochet et al. 2010, Brind'Amour et al. 2016).

Within the MSFD, suites of indicators of GES are outlined for commercial fish (Descriptor 3) and food webs (Descriptor 4) (European Commission 2010). The suite provided by the MSFD is considered a guideline that Member States must integrate with indicators relevant at regional and national level. Previous studies highlighted issues with one MSFD indicator, the large fish indicator (LFI; Shephard et al. 2011, ICES 2014), in particular due to the required assumption about threshold level, which is area-specific. In the Mediterranean Sea, for example, Spedicato et al. (2014) found that the LFI is sensitive to the choice of species inclusion and to the threshold level. Recent research identified typical length (TyL), an indicator of the size structure of fish community, as a potential alternative 
which might provide similar results and avoid problematic assumptions (ICES 2014, Lynam and Rossberg 2017, ICES 2018).

This paper aims to explore six indicators representing the size structure of the fish community: TyL, mean maximum length (MML), the LFI, the large species indicator (LSI), mean weight and evenness. This set includes the size structure indicators currently recommended by the MSFD (LFI and MML) and a selection of potential alternative or complementary length-based indicators for monitoring GES at national, regional or European level (ICES 2014, Lynam and Rossberg 2017, ICES 2018). In this paper we estimated these six indicators for 17 geographical sub-areas (GSAs) in the northern Mediterranean Sea, using data of lengthfrequency distributions obtained from the MEDITS experimental trawl survey.

Given the emerging role of length-based indicators and their demand for complementing the MSFD at regional level, this study sets three goals. First, to evaluate which length-based indicators are essential and sufficient to explain the status and impacts of the Mediterranean Sea demersal fish community; second, to determine whether hidden common trends detected through dynamic factor analysis (DFA) across Mediterranean GSAs can be explained by basin-scale pressure indicators; and third, to determine whether TyL, proposed by ICES as an alternative to LFI, could be useful in the Mediterranean to complement or replace existing MSFD indicators.

\section{MATERIALS AND METHODS}

\section{Data}

The MEDITS bottom trawl survey data used in this paper were collected in 17 GSAs (according to the GFCM classification, GSAs 1, 2, 5, 6, 7, 8, 9, 10, 11, 15, $16,17,18,19,20,22-23$ and 25) following a random depth-stratified sampling and using a gear with a common design (Spedicato et al. 2019). Data relevant for this study were stratum, depth, latitude, longitude, number and weight of individuals caught by species, individual length, sex and maturity stage for a list of target species. The biological data were collected following a common protocol (MEDITS Handbook; Anonymous 2017). We used the time series from 1999 to 2015 , to include the largest number of GSAs and target species.

The pressure indicators explored to explain common trends were environmental and exploitation proxies. In particular, we used the North Atlantic Oscillation (NAO) index, sea surface temperature (SST), the annual average SST anomaly of the Mediterranean Sea (Med anomaly), and as a proxy for fishing intensity, the fleet capacity. The NAO index was obtained through the Climatic Research Unit NAO website (https:/crudata.uea. ac.uk/ timo/datapages/naoi.htm). Med anomaly data were obtained from the European Environment Agency website (http://www.eea.europa.eu). The SST time series was obtained as average of the SST reprocessed in the Mediterranean Sea from the Copernicus website (http://www.copernicus.eu/). Data to derive fleet ca- pacity (expressed as $\mathrm{N}$ of vessels $\times \mathrm{GT} \times \mathrm{Kw}$, where GT is the gross tonnage in tons and $\mathrm{Kw}$ is the engine power in kilowatt) were obtained from the fishing capacity time series of the Community Fishing Fleet Register (CFFR 2019) after merging ports and landing sites at country and GSA level. The use of a combined metric for fleet capacity was applied to better differentiate pressure at sub-regional level and because it was more sensitive to changes over time.

\section{Fish community indicators based on size structure}

The analysis included data on bony and cartilaginous fish species, mostly but not limited to the commercially important ones, which have been MEDITS target species since 1999 (Supplementary material Table S1). The same species were used throughout the survey time series to avoid potential bias due to changes of target species in the MEDITS reference list over time.

The indicators were calculated from the lengthfrequency distributions $\left(\mathrm{N} \mathrm{km}^{-2}\right)$ according to Souplet (1996). The size structure indicators considered in the analyses are summarized in Table 1. The resulting dataset include a time series for each of the six indicators in each of the 17 GSAs.

\section{Principal component analysis (PCA)}

PCA was applied to select the minimum number of indicators to detect common trends among the GSAs and to reduce any redundancy in the six metrics considered. Redundancy may occur because several indicators are related to the relative abundance of large species. Data were first explored to check that the assumptions required to apply factor analysis were satisfied. The correlations among the six indicators for each GSA were tested using the Pearson coefficient. Next, data adequacy for the analysis was tested by the Kaiser-Meyer-Olkin (KMO) test (Kaiser 1974). This test measures sampling adequacy for the model and for all variables. The statistic is a measure of the proportion of variance among variables that might be common variance. The higher the KMO, the more suited the data are considered (Table S2).

The assessment of redundancy was performed through the Bartlett test, which compares the observed correlation matrix with the identity matrix. If the variables are perfectly correlated, only one factor is sufficient. If all the variables are orthogonal, we need as many factors as variables. In order to select the number of factors for the PCA, the Kaiser criterion (Yong and Pearce 2013) was applied, retaining only the eigenvalues at least equal to one. Finally, the PCA was carried out including GSA and year as qualitative variables in order to detect separation among the GSAs according to the estimates of the six indicators and possibly a year effect.

\section{Dynamic Factor Analysis (DFA)}

DFA is a multivariate time-series technique used to detect $M$ hidden common trends in a set of $N$ time 
Table 1. - Indicators of size structure at community level. ${ }^{1}$, The threshold used for all the GSAs was $30 \mathrm{~cm}$ total length (TL) i.e. the value that returned the highest $\mathrm{R}^{2}$ in the fitting of the $6^{\text {th }}$ degree polynomial in 8 out of 17 GSAs (for 6 GSAs it was $40 \mathrm{~cm}$ TL and for 3 was 35 cm $\mathrm{TL}) ;{ }^{2}$, In this study g was set $=45 \mathrm{~cm}$ TL, which is the $25^{\text {th }}$ percentile of the $L_{\text {max }}$ observed in the 17 GSAs under study for the species in Table $\mathrm{S} 1$ over the years.

\begin{tabular}{|c|c|c|c|c|}
\hline Indicator & Semantic definition & Equation & Reference & Interpretation \\
\hline $\begin{array}{l}\text { Large fish } \\
\text { indicator }\end{array}$ & $\begin{array}{l}\text { Proportion of fish } \\
\text { biomass larger than } \\
\text { a set threshold. }\end{array}$ & $\begin{array}{l}\operatorname{LFI}(t)=\sum_{l>l b i g} y_{l}(t) / y(t) \\
\text { lbig threshold } 1 ; \\
y_{l}(t) \text { catch per length class } l \text {; } \\
y(t) \text { total catch (measured species). }\end{array}$ & $\begin{array}{l}\text { ICES } 2014 \\
\text { Shephard et al. } \\
2011 \\
\text { OSPAR } 2017\end{array}$ & $\begin{array}{l}\text { A decrease in the LFI could be } \\
\text { due to increasing exploitation. } \\
\text { Exploitation reduces the biomass } \\
\text { contribution to the community } \\
\text { of the larger individuals/species } \\
\text { (Shephard et al. 2011). }\end{array}$ \\
\hline $\begin{array}{l}\text { Typical } \\
\text { length }\end{array}$ & $\begin{array}{l}\text { Geometric mean } \\
\text { length of fish } \\
\text { community, } \\
\text { weighted by body } \\
\text { mass. }\end{array}$ & $\begin{array}{l}T y L=\exp \left[\frac{\sum_{i=1}^{N} M_{i} \ln \left(L_{i}\right)}{\sum_{i=1}^{N} M_{i}}\right] \\
N \text { number of individuals in the distribution; } \\
M_{i} \text { body mass of the } i \text {-th fish; } \\
L_{i} \text { denotes the length of the } i \text {-th fish. }\end{array}$ & $\begin{array}{l}\text { ICES } 2014 \\
\text { OSPAR } 2017\end{array}$ & $\begin{array}{l}\text { TyL measures the size structure of } \\
\text { fish and elasmobranch communities } \\
\text { and decreases under high fishing } \\
\text { pressure (OSPAR 2017, Lynam and } \\
\text { Rossberg 2017). }\end{array}$ \\
\hline Evenness & $\begin{array}{l}\text { Measure of the } \\
\text { equitability in } \\
\text { relative abundance } \\
\text { among the length } \\
\text { classes. }\end{array}$ & $\begin{array}{l}E=\frac{H^{\prime}}{H_{\max }^{\prime}} ; \quad H^{\prime}=-\sum_{i=1}^{S} p_{i} \ln p_{i} \\
H_{\max }^{\prime}=\ln (S) \\
S \text { is the number of lengths in the fish } \\
\text { assemblage; } \\
p_{i} \text { is the proportion of individuals in the } i \text {-th } \\
\text { length class. }\end{array}$ & Pielou 1966 & $\begin{array}{l}\text { Reduction in evenness should } \\
\text { reflect increasing dominance of } \\
\text { the community by small-bodied, } \\
\text { fast-growing, highly productive } \\
\text { species caused by increased fishing } \\
\text { mortality (Greenstreet et al. 2012b). }\end{array}$ \\
\hline $\begin{array}{l}\text { Mean } \\
\text { maximum } \\
\text { length }\end{array}$ & $\begin{array}{l}\text { Mean maximum } \\
\text { length in the } \\
\text { community. }\end{array}$ & $\begin{array}{l}\overline{L_{\max }}=\sum_{j}\left(L_{\max j} N_{j}\right) / N \\
L_{\max j} \text { is the maximum length obtained by } \\
\text { species } j ; \\
N_{j} \text { is the number of individuals of species } j \text {; } \\
N \text { is the total number of individuals. }\end{array}$ & ICES 2012 & $\begin{array}{l}\text { A decline in the MML indicates } \\
\text { that the abundance of the most } \\
\text { vulnerable fish and elasmobranch } \\
\text { species is decreasing, leading to a } \\
\text { change in the species composition } \\
\text { (OSPAR 2017, Lynam and } \\
\text { Rossberg 2017) caused by } \\
\text { increasing fishing pressure (Shin et } \\
\text { al. 2005). }\end{array}$ \\
\hline $\begin{array}{l}\text { Large } \\
\text { species } \\
\text { indicator }\end{array}$ & $\begin{array}{l}\text { Biomass proportion } \\
\text { of large species in a } \\
\text { community. }\end{array}$ & $\begin{array}{l}L S I=\frac{\sum_{i} B_{i}\left(L_{\max }>g\right)}{\sum_{i} B_{i}} \\
B_{i} \text { is the biomass of species } i \text { having } L_{\max } \\
>\mathrm{g}^{2} .\end{array}$ & $\begin{array}{l}\text { Shephard et al. } \\
2011\end{array}$ & $\begin{array}{l}\text { A decline in LSI should indicate } \\
\text { a decrease in the biomass of } \\
\text { the predator species in the fish } \\
\text { community (Shephard et al. 2011). }\end{array}$ \\
\hline Mean weight & $\begin{array}{l}\text { Mean weight in the } \\
\text { community. }\end{array}$ & $\begin{array}{l}M W=\frac{\sum_{i} B_{i}}{\sum_{i} N_{i}} \\
B_{i} \text { is the biomass index of species } i \\
N_{i} \text { is the abundance. }\end{array}$ & $\begin{array}{l}\text { Rochet and } \\
\text { Trenkel } 2003\end{array}$ & $\begin{array}{l}\text { A decreasing trend could be } \\
\text { a signal of removal of larger } \\
\text { individuals (Rochet and Trenkel } \\
\text { 2003). }\end{array}$ \\
\hline
\end{tabular}

series (Zuur et al. 2003). This analysis was applied to the standardized (mean 0 and a standard deviation 1) indicators linked to the principal components of the PCA. For each indicator, a DFA was carried out among the estimates of the 17 GSAs. Each group of 17 times series was modelled according to a generalized formulation in terms of linear combinations of $M$ common trends (from 1 to 3 trends), 4 explanatory variables (NAO index, Med anomaly, SST and fleet capacity), factor loadings (on trends and covariates), an offset and an observation error. Up to three explanatory variables were combined simultaneously. SST and Med anomaly were never combined due to their strong correlation. The mathematical formulation for this model is:

$$
y_{t}=Z x_{t}+D d_{t}+a_{t}+v_{t}
$$

where $y_{t}$ is a $N \times 1$ vector containing the values of the indicator for the 17 GSAs $(N=17), x_{t}$ is an $M \times 1$ vector containing the values of the $M$ common trends at time $t, Z$ is an $N \times M$ matrix containing the factor loadings on the $M$ common trends, $d_{t}$ is an $M \times 1$ vector with the values of the four covariates at time $t, D$ is a $N \times M$ matrix containing the factor loadings on covariates, $a_{t}$ is the offset and $v_{t}$ is the observation error distributed as a multivariate normal distribution with mean 0 and covariance matrix R.

Four different hypotheses on the covariance matrix of the observation error were tested:

- same variance and no covariance (diagonal-equal);

- different variances and no covariance (diagonal-unequal);

- same variance and covariance (equalvarcov); and - different variances and covariance (unconstrained).

All combinations of covariates (included at their original scale) were considered for a total of $12 \mathrm{com}$ binations (with $0,1,2$ or 3 covariates). A total of $12 \times 4$ (covariance models) $\times 3$ (number of trends) models was tested. The performance of the models was evaluated according to the corrected Aikake information criterion (AICc; Burnham and Anderson 2002), following Zuur 
et al. (2003) and Holmes et al. (2018).

The normality of residuals of the best model was tested through the Shapiro-Wilk test. In cases of deviation of residuals from the normal distribution, a scale finite mixture model (McLachlan and Peel 2000) was applied (Supplementary Material Section 5).

The investigation of the canonical correlations between detected common trends and explanatory variables followed Zuur et al. (2003), as another way of detecting their effects on dependent variables. For this reason, the relationship between the trends in the selected model (without covariates) and the covariates was tested with Pearson canonical cross correlations, also considering a time lag, set alternatively at 1,5 or 10 years to account for lags between drivers and response due to biological processes. Ten years is the average lifespan (Table S3) of the demersal fish community weighed by their abundance $\left(\mathrm{N} \mathrm{km}^{-2}\right)$. Since individuals subject to an impact are expected to be no longer in the population after their average lifespan, this metric can identify patterns attributable to a lasting change in the community, i.e. a trans-generational effect of the given impact. Biomass and abundance trends by species were compared with indicator trends to detect the species driving such trends. The mean temperature in the catch from Cheung et al. (2013) was used as a proxy for thermal preference of the species driving the trends to help the interpretation of the results (Table S4).

All the analyses were carried out in the R environment (R Core Team 2019). The FactoMineR R library (Lê et al. 2008) was used for PCA, the Hmisc R library (Harrell et al. 2006) for correlation analyses and the MARSS R library (Holmes et al. 2018) for DFA.

\section{RESULTS}

\section{Principal component analysis}

The Pearson correlation coefficient showed several strong correlations among variables (Table S5). In almost all the GSAs the evenness was significantly and positively correlated with mean weight $(\mathrm{p}<0.05)$, while the LFI was significantly $(\mathrm{p}<0.05)$ and positively correlated with TyL, with the only exception of GSA 2 (Table S5).

For all GSAs the Kaiser criterion suggested the use of two factors, except for GSAs 1, 5, 15, 19 and 25, for which the use of only one factor was suggested. Thus, two factors were used for the PCA. The variance explained by the first component was $66.4 \%$, while the variance explained by the second one was $20.9 \%$, for a cumulative variance of $87.4 \%$ (Fig. 1 and Table 2).

Year did not seem to influence the grouping of the data $(p<0.05)$, with all years clustered in the centre of the PCA space (Fig. 1B). Conversely, GSA was significantly correlated with both dimensions (Fig. 1B). The eastern and central Mediterranean (in particular GSAs $17,18,19,20,22+23$ and 25 ) were characterized by the first coordinate negative and the second one between -2 and 1, while the western Mediterranean (specifically, GSAs 1, 2, 5, 7, 9 and 11) was characterized by positive first coordinate and second coordinate widely

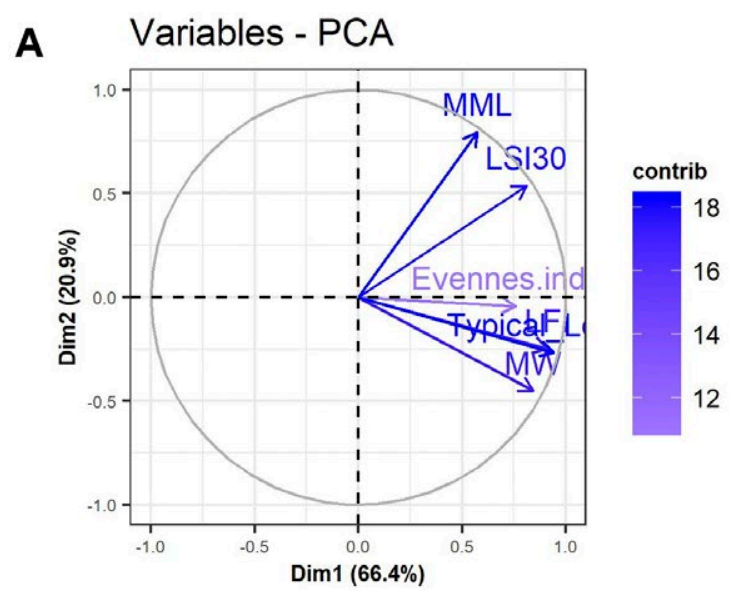

B PCA factor map

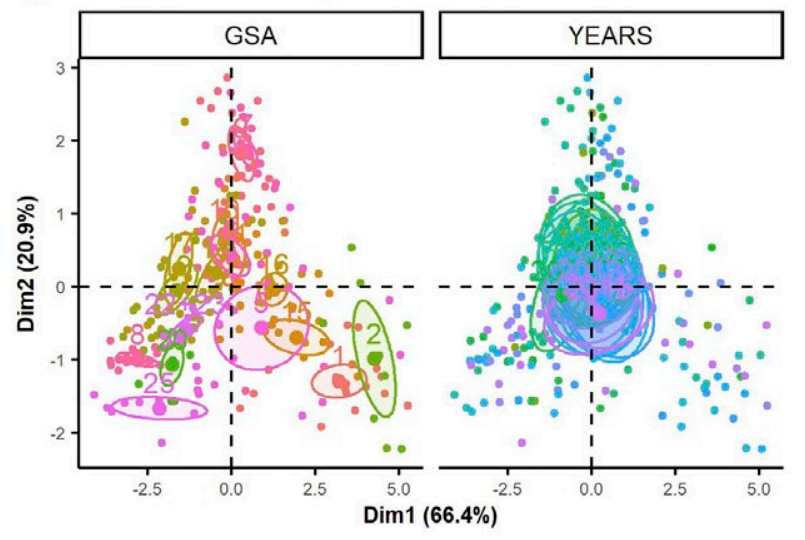

Fig. 1. - PCA results. A, distribution of the six indicators, TyL, LSI, MW, LFI, evenness and MML, on the principal component axes. The variance explained by each axis in \% is reported along the two dimensions. B, scattered data points grouped by the 17 GSAs and 17 years used as qualitative covariates.

Table 2. - PCA results: correlation of indicators, GSA and years with two principal components. Explained deviance: first component $66.4 \%$, second component $20.9 \%$, cumulative $87.4 \%$.

\begin{tabular}{lcc}
\hline Variables & \multicolumn{2}{c}{ Correlation } \\
\hline TyL & Dim1 & Dim2 \\
LSI & 0.94 & -0.27 \\
MW & 0.91 & 0.54 \\
LFI & 0.84 & -0.45 \\
Evenness & 0.81 & -0.25 \\
MML & 0.76 & Not significant \\
GSA & 0.57 & 0.79 \\
YEARS & 0.74 & 0.76 \\
\% explained variance & Not significant & -0.17 \\
\hline
\end{tabular}

ranging (Fig. 1B). TyL had the highest correlation with the first principal component, while MML had the highest correlation with the second component.

The PCA results separated the six indicators into two groups: one represented by indicators sharing a definition explicitly based on the $\mathrm{L}_{\max }$ parameter that focuses on the fraction of the community with large species (MML and LSI). The other group included indicators not based on $\mathrm{L}_{\max }$. The subsequent analyses were carried out considering TyL and MML, the indicators most correlated with the principal components and the least correlated with each other. Each indicator 

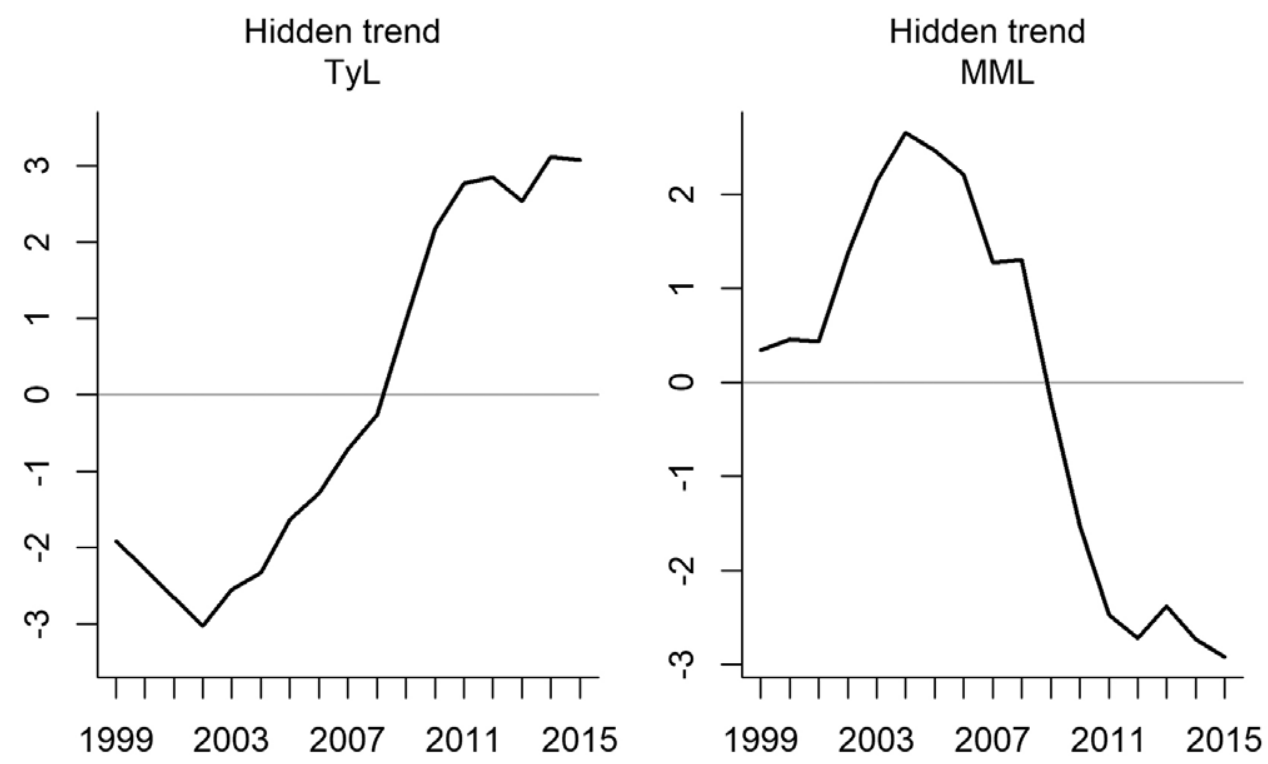

Fig. 2. - Underlying common trends over the time period 1999-2015 detected by DFA for the indicators TyL and MML.

represented one of the groups detected in the PCA. Dynamic factor analysis

The DFA results showed that the TyL trend decreased between 1999 and 2002 and increased steadily afterward, while the MML trend increased until 2004 before declining sharply between 2008 and 2012 (Fig. 2).

The comparison among the models tested for TyL and MML showed that for both indicators the covariates did not improve the goodness of fit, giving an AICc higher than the baseline model. In Table S8, the best models are reported for each type (defined by the included covariates). The best model is characterized by one underlying common trend $(M=1)$ for each indicator with the covariance matrix "diagonal and equal".

The common trends detected can be decomposed to effects at each GSA level through the factor loadings
(Fig. 3), representing the contribution of each GSA to the common trend. In GSAs 2, 17, 19 and 22+23, TyL was poorly influenced by the common trend (with factor loading below 0.2 in absolute value), while GSAs $1,5,10,16,18$ and 25 had a factor loading higher than 0.2 (Fig. 3). The factor loadings estimated for TyL on the common trend showed that in the western Mediterranean this indicator is associated with the trend (with the exception of the Balearic Islands, GSA 5), while in the central Mediterranean TyL was inversely associated with the common trend in GSAs 18 and 20, and positively in GSAs 16 and 25.

The factor loadings of the MML indicated that most GSAs were associated with the hidden common trend, except GSA 1, 15, 16 and 25 (Fig. 3). The MML in GSAs 2, 8, 11 and 22+23 was poorly correlated with the common trend, while GSAs 1, 5, 6, 16, 17, 18, 19,
Factor loadings on trend 1 TyL

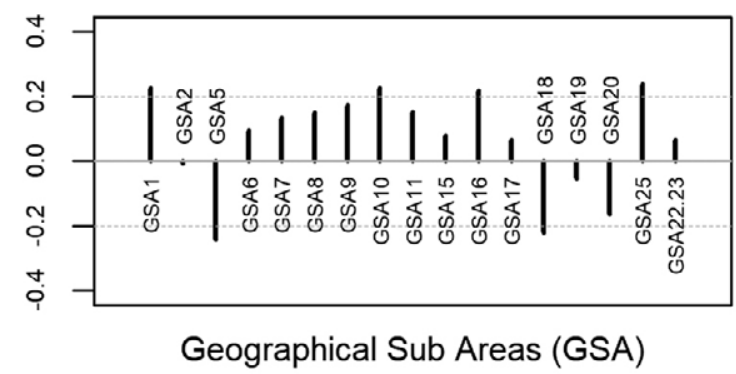

Factor loadings on trend 1 MML

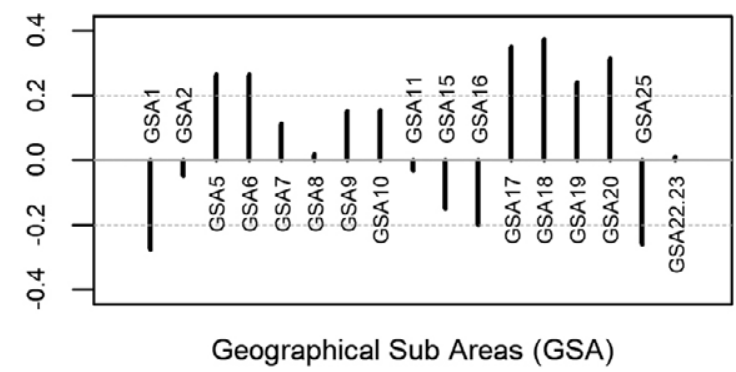

\begin{tabular}{|c|c|c|c|c|c|c|c|c|c|c|c|c|c|c|c|c|}
\hline GSA1 & GSA2 & GSA5 & GSA6 & GSA7 & GSAB & GSA9 & GSA10 & GSA11 & GSA15 & GSA16 & GSA17 & GSA18 & GSA19 & GSA2O & GSA25 & GSA22.23 \\
\hline 0.23 & -0.01 & -0.24 & 0.09 & 0.13 & 0.15 & 0.17 & 0.23 & 0.15 & 0.08 & 0.22 & 0.07 & -0.22 & -0.05 & -0.16 & 0.24 & 0.07 \\
\hline-0.28 & -0.05 & 0.27 & 0.26 & 0.11 & 0.02 & 0.15 & 0.15 & -0.03 & -0.15 & -0.20 & 0.35 & 0.38 & 0.24 & 0.32 & -0.26 & 0.01 \\
\hline
\end{tabular}

Fig. 3. - Factor loadings on the hidden common trend for TyL and MML. Top panel: values of factor loadings for the two indicators per GSA Bottom panel: barplots with individual bars representing GSAs with values above \pm 0.2 (marked by dotted horizontal lines) are considered indicative of a positive/negative effect (reported in bold in the table). 


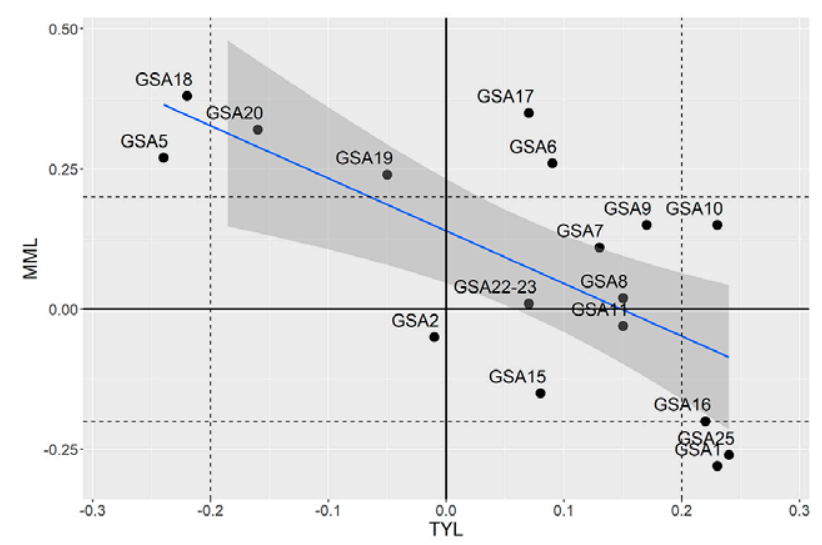

Fig. 4. - Factor loadings for the two indicators by GSA. Linear smoothing overlapped to show the linear relationship. Values above \pm 0.2 , marked with black dashed lines, are considered indicative of a positive/negative effect.

20 and 25 had a factor loading higher than 0.2 in absolute value. The factor loadings for the two indicators showed a significant negative relationship $(\mathrm{r}=-0.68$; $\mathrm{p}<0.01$; Fig. 4).

\section{Correlations between trends and covariates}

The covariates SST and Med anomaly were highly correlated with each other, and both showed a strong negative correlation with the fleet capacity (Fig. S8 and Table S9), with opposite patterns in time (Fig. S9). NAO showed no correlation with other covariates and no clear temporal patterns. The common trends for TyL and MML detected by the DFA were compared with the covariates under consideration (SST, NAO, Med anomaly and fleet capacity) through canonical correlations between the detected trends and the covariates. A significantly strong positive correlation was found between the trend of TyL and the covariates Med anomaly and SST, while a negative correlation was found between TyL and fleet capacity (Table 3). The hidden trend detected for MML was significantly correlated with the same covariates, but inversely.

\section{Correlations between changes of species abundance and selected indicators}

In GSAs $1,7,8,9,10,11,15,16$ and 25, where TyL increased consistently with the common trend, TyL was strongly influenced by three species characterized by higher biomass: Galeus melastomus, Pagellus erythrinus and Mullus barbatus (Figs S2 and S4).

In GSA 5 the increase in S. smaris (Tables S6 and S7) produced a decrease in MML (Fig. S3), this species being very important in terms of abundance (more than in biomass) in this GSA, while in GSA 1 the increase in $G$. melastomus and the decrease in P. acarne led an increase in MML. The abundance trend of M. merluccius in GSA 16 and 17 (respectively increasing and decreasing, Tables S6 and S7) influenced the trend of MML, while in GSA 18 the increasing trend of density of $M$. barbatus and S. flexuosa returned a decreasing
Table 3. - Canonical Pearson correlation between the common trend detected by DFA for the two indicators, TyL and MML, with no time lag and a 1-year, 5-year and 10-year lag. The significant $(p<0.05)$ correlations are indicated in bold.

\begin{tabular}{llcccc}
\hline & Covariates & no lag & 1-year lag & 5-year lag & 10 -year lag \\
\hline TyL & NAO & 0.12 & -0.11 & -0.33 & -0.37 \\
& MedAnomaly & $\mathbf{0 . 7 2}$ & $\mathbf{0 . 7}$ & $\mathbf{0 . 5 9}$ & $\mathbf{0 . 7 6}$ \\
& Fleet_cap & $\mathbf{- 0 . 9 4}$ & $\mathbf{- 0 . 9}$ & $\mathbf{- 0 . 6}$ & $\mathbf{- 0 . 7 2}$ \\
SST & $\mathbf{0 . 6 2}$ & $\mathbf{0 . 5 8}$ & $\mathbf{0 . 6}$ & $\mathbf{0 . 7 5}$ \\
MML & -0.23 & 0.02 & 0.4 & 0.2 \\
& NAO & $\mathbf{- 0 . 6 9}$ & $\mathbf{- 0 . 6 5}$ & -0.32 & $\mathbf{- 0 . 6 1}$ \\
MedAnomaly & $\mathbf{- 0 . 9 2}$ & $\mathbf{0 . 8 9}$ & $\mathbf{0 . 5 3}$ & 0.45 \\
& Fleet_cap & $\mathbf{0 . 9 2}$ & -0.44 & -0.36 & $\mathbf{- 0 . 5 9}$ \\
SST & $\mathbf{- 0 . 5}$ & -0.46 &
\end{tabular}

trend of MML.

In GSA 19 the decreasing trend in MML was influenced by the increase in S. smaris, S. flexuosa, M. barbatus and P. acarne.

Contrasting patterns between areas were observed in the comparison between TyL and MML. In some GSAs, increasing trends of species showing both high abundance and biomass led to an increase in both indicators. This was the case for G. melastomus (in GSAs 1 and 10) and M. merluccius (in GSAs 10 and 16), both species with high $L_{\max }$. Conversely, in GSA 18 and 19 the increase in small-sized and thermophile species such as $M$. barbatus and $P$. acarne led to a decrease in both MML and TyL, these species being the most abundant in both abundance and biomass and characterized by low $L_{\max }$ (Table S5 and S6). A more complex situation was found in GSA 6, where TyL increased but MML decreased. This could be attributed to the fact that both abundance and biomass of M. merluccius declined with a sharper decline in abundance (Figs S2 and S3), entailing an increase in mean weight, and hence length.

\section{DISCUSSION}

We estimated a set of six size structure indicators of the fish community which are considered useful to detect changes at population and community level and are among those assessed by OSPAR (2017) and by the ICES Working Group on Ecosystem Effects of Fishing Activities (WGECO) (ICES 2014, 2018).

The first goal of this study was to address the redundancy within this set of proposed indicators in order to select those that effectively summarize the fish community dynamics over time. Previous studies used factor (Greenstreet et al. 2012b) and ordination techniques such as non-metric multidimensional scaling (Blanchard et al. 2010) to address indicator redundancy and compare the community size structure of different ecosystems. We, instead, combined different statistical techniques. Firstly, we used a factor technique (PCA) to select a non-redundant subset of two size-structure indicators of fish community. TyL and MML were found to be the indicators most linked to the principal components. Secondly, we explored the occurrence of common trends among the GSAs through DFA on the two selected indicators, following Zuur et al. (2003). The selected models were characterized by only one common trend, while Zuur et al. (2003) found three common trends in their analysis. 
The capability of DFA to identify more common trends in our case might be limited by the spatial and temporal scale of the analysis: the fine-scale geographical patterns shown by PCA are not captured by DFA. Moreover, the relatively short time series lacking contrasted patterns and the fact that the indicators smooth over the trends of individuals species might limit the capability of capturing potential additional trends that may be masked by the main common trend. While the two selected indicators are expected to show community-wide improvement upon reduction of fishing pressure, here we found asynchronous and contrasting patterns. This result could be explained by the second goal of our study: to explore through DFA the relationships between the common trends detected among the GSAs for the two selected indicators and the times series of environmental and anthropogenic drivers at basin scale. While DFA showed no significant link between the indicators and the covariates, correlation analysis revealed significant relationships. As observed by Zuur et al. (2003), the fact that the tested models incorporating covariates were not selected as the best models does not necessarily mean that these covariates had no influence on the time series. The higher AICc for the models including covariates could indicate that the explanatory variables did not produce an overall improvement in the model, the covariates being related to only some of the time series. Indeed, for both selected indicators, the inclusion of each covariate implies the estimation of 17 extra parameters (one for each GSA), which could make the model worse for covariates not linked to all the time series. This implies that the relationship between trends and covariates is area-specific, as also confirmed by the fact that the factor loadings seem to show geographical patterns: TyL is related to the common trend positively in most western Mediterranean GSAs and negatively in the eastern Mediterranean ones (Fig. 3). Different patterns between the eastern-central Mediterranean and the western Mediterranean also emerged from the PCA (Fig. 1B). Similarly, sub-regional patterns were observed in the North Sea, where OSPAR (2017) highlighted that the increasing TyL trend observed in northern areas was not observed in southern areas.

The fleet capacity showed a strong negative correlation with the trend detected for TyL. This result indicates that the increase in TyL (Fig. S2) observed in 10 out of 17 GSAs (mostly in the western Mediterranean) could be associated with a decrease in fleet capacity. This effect could be confounded with that determined by the increasing SST: TyL is indeed linked to the biomass of the fish community and thus strongly influenced by the species with higher biomass, which in the western Mediterranean include thermophile species such as $P$. erythrinus and M. barbatus (Fig. S4; Cheung et al. 2013). Notably, in the last few decades, landings of thermophile species in the Mediterranean have increased, contrasting with a general decrease in landings and a widely reported impact of increasing temperature on species and ecosystems (e.g. Vasilakopoulos et al. 2017). However, the increasing trend of biomass in our case is observed also for non-thermophile species such as $G$. melastomus, $S$. smaris and, to a smaller extent, $L$. piscatorius and L. budegassa. Therefore, the increasing common trend detected in TyL is most likely due to a decrease in fishing pressure, although a synergic effect with SST cannot be excluded for some species.

Conversely, MML showed a positive correlation with fleet capacity. Based on its definition, MML is expected to decline with an increase in fishing pressure, so the reduction in fishing effort observed in all GSAs is expected to result in an increase in MML. Instead, a decrease was observed for the general trend (Fig. 3) and for the majority of sub-areas (GSA 5, 6, 7, 9, 10, 17, 18, 19, 20; Fig. S7), indicating an asymmetric response of MML to increasing and decreasing pressures. MML is related to the abundance of species characterized by large maximum size $\left(L_{\max }\right)$, which generally also show slow growth and late maturation (Winemiller and Rose 1992). We can therefore expect a lag between a decrease in fishing pressure and an increase in MML. The decrease in the observed correlation with a time lag of 5 and 10 years (Table 3 ) is consistent with our hypothesis. The observed pattern could also indicate an increase in the abundance of species characterized by small $L_{\max }$. These generally show a faster positive response to reduction in fishing pressure than species with large $L_{\max }$, and thus an increase in abundance of the former leads in the short term to a decrease in MML. This pattern, known for other areas (OSPAR 2017), emerges in individual examination of GSAs (Table S5 and S6), where the dynamics of the most abundant species, such as $M$. barbatus and $S$. smaris, explain indicator patterns. The trend of MML therefore seems to be driven by these two contrasting factors, which act synergistically to produce the observed asymmetric response to decreasing pressure. Contrary to the expectation, a reduction in fishing pressure leads to an initial decline of MML driven by an increase in small, short-living species caused by release of fishing pressure. Not before several years, an increase in MML can be expected as the large fish species recover. In our case, with a lag of 10 years, the trend shows signs of inversion, with loss of the positive correlation between decreased fishing pressure and decreased MML. While this pattern might be driven by an increase in small species with preference for high SST, in our case the small species that showed an increase in abundance include both thermophile species (e.g. M. barbatus) and non-thermophile species (e.g. $S$. smaris; Table S3), indicating that SST does not explain the increasing patterns for all the small species.

The declining pattern in MML observed in GSA 6 and attributed to the faster decline in abundance than in biomass of $M$. merluccius could be indicative of fishing pressure targeting smaller individuals (for example, if larger individuals are distributed in areas not reached by trawlers), but could also be driven by a succession of poor recruitments (Lynam and Rossberg 2017).

The two indicators selected by our analysis correspond to those currently proposed by OSPAR and ICES WGECO. MML, in particular, is recommended by the MSFD to assess objective 3.3, "population age 
and size distribution", to account for the relative abundance of old, large fish in the community. Maximum length is considered a proxy for species vulnerability, as species with larger maximum length given their life history traits tend to be more vulnerable to fishing. These species are also expected to be the first to decline under high fishing pressure, with a decline in MML implying a decrease in abundance of the most vulnerable fish species (OSPAR 2017).

A complementary indicator that can account for changes in size structure has traditionally been identified in the LFI (European Commission 2010, OSPAR 2017), currently included for MSFD Descriptor 4 (namely, 4.2.1). Recent research has however identified some difficulties related to the implementation of the LFI for the MSFD. Critically, the determination of the threshold for what constitutes a "large fish" is prone to arbitrary choices. Furthermore, methods developed for estimation of this parameter have revealed sensitivity to the fish communities studied, to the species included and to the length of the time series (Shephard et al. 2011, Spedicato et al. 2014), rendering a standardized definition between areas problematic. Despite the fact that we calculated LFI by applying a $6^{\text {th }}$ degree polynomial for optimal threshold determination, as suggested by Shephard et al. (2011), the LFI was not selected in our analysis. TyL has been suggested to replace or complement the LFI. While possessing similar statistical properties to the LFI, TyL is considered more robust to the LFI's limitations (ICES 2014, Lynam and Rossberg 2017, ICES 2018).

Our analysis improves present comprehension about the performance of TyL and LFI for Mediterranean demersal fish community, showing that the TyL has lower overlap with other indicators, emerging as a potential alternative. Additionally, our study confirms the complementarity of TyL to MML, already highlighted by Lynam and Rossberg (2017), because the joint application of both indicators can help disentangle changes in community composition from changes in size structure.

Finally, we highlight three general aspects pertaining to the indicators' capability to track the responses of the system to different exogenous and endogenous drivers. First, indicators are generally developed and defined to track community response to increasing pressure, whereas the effect of pressure release is rarely assessed and generally assumed to be inverse to pressure increase. We propose that indicators can behave asymmetrically to increasing and decreasing pressures: while most indicators can generally track a decline in community status due to increasing pressure, they might differ in their capability to capture community response to pressure release. In our study, for example, MML patterns might be indicative of a time-lagged response to decreasing pressure. There is limited understanding of indicators' responsiveness to decreasing pressures (Lynam and Rossberg 2017, OSPAR 2017), and the choice of indicators rarely takes this characteristic explicitly into account, as shown by their definitions (Table 1). Our study suggests that MML might perform worse (i.e. slower) than TyL in capturing a community's recovery after fishing pressure reduction. Nominal effort reduction is assumed to correspond to a reduction in fishing pressure in our study. Effort and fishing mortality, however, cannot be linearly related and the observed delay might be due to reduction in fishing mortality declining less rapidly than decline in effort. Nevertheless, our metric of fleet capacity emphasizes the capacity of larger, more powerful boats, which exert the bulk of the pressure on the stocks. Combined metrics of fleet capacity is thus a better proxy of fishing impact than other metrics of fishing effort.

Second, the complementarity between indicators in responsiveness should be accounted for. We show that the indicators' complementarity should extend to the capability to account for impacts across different time lags: MML shows a likely time-lagged response to pressure reduction, while the trend of TyL is associated with fast response of large-sized species to changes in fishing pressure and/or environmental conditions. This aspect is critical, as the responsiveness of indicators is therefore vulnerable to the length of time series, masking relationships or leading to spurious relationships and potentially confounding the interpretation of indicators (see for example the positive correlation between MML and fleet capacity).

Third, we highlight how definitions do not consider multiple stressors, so combinations of SST and effort can have antagonistic/synergistic effects, leading to an unclear interpretation of the indicators' trends. OSPAR (2017) noted that the influence of SST and fishing on TyL can be hard to disentangle. In our study, we were able to tell the two drivers apart by taking into account the thermal preference of increasing species. We noted that the increase in TyL could mainly be attributed to decline in fishing pressure rather than increase in SST or, at best, to synergistic effects for a few species. Similarly, also for MML we determined that the observed changes could not be univocally driven by increase in SST: in fact, the increase in abundance potentially driving the MML pattern was observed in small-sized thermophile and non-thermophile species alike. This would reinforce the hypothesis of the increase in small species following fishing pressure release. Only through knowledge of the underlying biology of the species can we disentangle drivers' effects on species patterns.

Overall, these considerations reinforce the importance of assessing the indicators' capability to capture trends across diverse ranges of time lags and to interpret their patterns according to multiple drivers, especially in light of changing communities driven by climatic change.

Our results strongly support the inclusion of TyL as one of the regional MSFD indicators for detecting changes in the demersal fish community throughout the Mediterranean Sea. The results of this study will therefore be of support to regional application of MSFD targets by reinforcing scientific knowledge of length-based indicators in Mediterranean Sea. Additionally, these results can be applied in the context of multiannual management plans, allowing community 
and ecosystem dynamics to be considered, as required by the Common Fishery Policy (EU Reg. 1380/2014). The identification of reference levels for these indicators remains a critical point to be addressed. For North Atlantic areas, reference levels for TyL, MML and the LFI have been identified (ICES 2018). In the Mediterranean, these values do not yet seem to have been determined (Dupont et al. 2018), and future studies should therefore focus on this issue at different spatial scales.

\section{ACKNOWLEDGEMENTS}

This study was conducted in the framework of the MEDITS Project. We are grateful to Cristina Garcia, Enric Massutì and Antonio Esteban from the Instituto Español de Oceanografía (IEO) for providing the data for the analyses and to all participants of the MEDITS project for collecting these data. We gratefully acknowlege two anonymous reviewers for their comments, which helped improve the manuscript.

\section{REFERENCES}

Anonymous. 2017. MEDITS Handbook. Version n. 9, MEDITS Working Group: 106 pp.

http://www.sibm.it/MEDITS\%202011/principaledownload.htm

Blanchard J.L., Coll M., Trenkel V.M., et al. 2010. Trend analysis of indicators: a comparison of recent changes in the status of marine ecosystems around the world. ICES J. Mar. Sci. 67: $732-744$.

https://doi.org/10.1093/icesjms/fsp282

Brind'Amour A., Rochet M.J., Ordines F., et al. 2016. Environmental drivers explain regional variation of changes in fish and invertebrate functional groups across the Mediterranean Sea from 1994 to 2012. Mar. Ecol. Prog. Ser. 562: 19-35. https://doi.org/10.3354/meps11912

Burnham K.P., Anderson D.R. 2002. Model Selection and Multimodel Inference. A Practical Information-Theoretic Approach. 2nd ed.. Springer, New York.

Cheung W.W.L., Watson R., Pauly D. 2013. Signature of ocean warming in global fisheries catch. Nature 497: 365-368. https://doi.org/10.1038/nature 12156

Cury P.M., Christensen V. 2005. Quantitative ecosystem indicators for fisheries management. ICES J. Mar. Sci. 62: 307-310. https://doi.org/10.1016/j.icesjms.2005.02.003

Dupont C., Barsoumian S., Moreira G., et al. 2018. Article 16 Technical Assessment of the MSFD 2015 reporting on Programme of Measures. Italy Report.

European Commission. 2010. EU Commission Decision of 1st September 2010 on criteria and methodological standards on good environmental status of marine waters (2010/477/EU). Off. J. Eur. Union, L232: 12-24.

European Union. 2013. Regulation (EU) No 1380/2013 of the European Parliament and of the Council of 11 December 2013 on the Common Fisheries Policy.

Fulton E.A., Smith A.D.M., Punt A.E. 2005. Which ecological indicators can robustly detect effects of fishing? ICES J. Mar. Sci. 62: $540-551$. https://doi.org/10.1016/j.icesjms.2004.12.012

Greenstreet S.P.R., Rossberg A.G., Fox C.J., et al. 2012a. Demersal fish biodiversity: species-level indicators and trends-based targets for the Marine Strategy Framework Directive. ICES J. Mar. Sci. 69: 1789-1801. https://doi.org/10.1093/icesjms/fss148

Greenstreet S.P.R., Fraser H.M., Rogers S.I., et al. 2012b. Redundancy in metrics describing the composition, structure, and functioning of the North Sea demersal fish community. ICES J. Mar. Sci. 69: 8-22. https://doi.org/10.1093/icesjms/fsr188

Harrell F.E. Jr. 2006. The Hmisc package. https://cran.r-project.org/web/packages/Hmisc/Hmisc.pdf

Holmes E., Ward E., Wills K. 2018. MARSS: multivariate autore- gressive state-space modeling. R package version 3.10.10. http://CRAN.R-project.org/package=MARSS

Houle J.E., Farnsworth K.D., Rossberg A.G., et al. 2012. Assessing the sensitivity and specificity of fish community indicators to management action. Can. J. Fish. Aquat. Sci. 69: 1065-1079. https://doi.org/10.1139/f2012-044

ICES. 2012. Report of the Working Group on the Ecosystem Effects of Fishing Activities (WGECO), 11-18 April, Copenhagen, Denmark. ICES CM 2012/ACOM:26. 192 pp.

ICES. 2014. Report of the Working Group on the Ecosystem Effects of Fishing Activties (WGECO), 8-15 April 2014, Copenhagen, Denmark. ICES CM 2014/ACOM:26. 174 pp.

ICES. 2018. Report of the Working Group on Ecosystem Effects of Fishing Activities (WGECO), 12-19 April 2018, San Pedro del Pinatar, Spain. ICES CM 2018/ACOM:27. 69 pp.

Kaiser H.F. 1974. An index of factor simplicity. Psychometrika 39: 31-36. https://doi.org/10.1007/BF02291575

Lê S., Josse J., Husson F. 2008. FactoMineR: An R Package for Multivariate Analysis. J. Stat. Softw. 25: 1-18. https://doi.org/10.18637/jss.v025.i01

Lynam C.P., Rossberg A.G. 2017. New univariate characterization of fish community size structure improves precision beyond the Large Fish Indicator. arXiv:1707.06569. http://arxiv.org/abs/1707.06569

McLachlan G., Peel D. 2000. Finite Mixture Models. John Wiley \& Sons. Hoboken, New Jersey. https://doi.org/10.1002/0471721182

Methratta E.T., Link J.S. 2006. Evaluation of quantitative indicators for marine fish communities. Ecol. Ind. 6: 575-588. https://doi.org/10.1016/j.ecolind.2005.08.022

OSPAR. 2017. Intermediate Assessment. Fish and food web. Last accessed: 12/07/2019.

https://oap.ospar.org/en/ospar-assessments/ intermediate-assessment-2017/biodiversity-status/ fish-and-food-webs/

Pielou E. 1966. The measurement of diversity in different types of biological collections. J. Theor. Biol. 13: 131-144. https://doi.org/10.1016/0022-5193(66)90013-0

R Core Team. 2019. R: A language and environment for statistical computing. R Foundation for Statistical Computing, Vienna, Austria. https://www R-project.org/

Rochet M.J., Trenkel V.M. 2003. Which community indicators can measure the impact of fishing? A review and proposals. Can. J. Fish. Aquat. Sci. 60: 86-99. https://doi.org/10.1139/f02-164

Rochet M.J., Trenkel V.M., Carpentier A., et al. 2010. Do changes in environmental and fishing pressures impact marine communities? An empirical assessment. J. Appl. Ecol. 47: 741-750. https://doi.org/10.1111/j.1365-2664.2010.01841.x

Shephard S., Reid D.G., Greenstreet S.P.R. 2011. Interpreting the large fish indicator for the Celtic Sea. ICES J. Mar. Sci. 68: 1963-1972. https://doi.org/10.1093/icesjms/fsr114

Shin Y.-J., Shannon L.J. 2010. Using indicators for evaluating, comparing, and communicating the ecological status of exploited marine ecosystems. 1. The IndiSeas project. ICES J. Mar. Sci. 67: 686-691. https://doi.org/10.1093/icesjms/fsp273

Shin Y-J., Rochet M.J., Jennings S., et al. 2005. Using size-based indicators to evaluate the ecosystem effects of fishing. ICES J. Mar. Sci. 62: 384-396. https://doi.org/10.1016/j.icesjms.2005.01.004

Shin Y.J., Houle J.E., Akoglu E., et al. 2018. The specificity of marine ecological indicators to fishing in the face of environmental change: A multi-model evaluation. Ecol. Ind. 89: 317-326. https://doi.org/10.1016/j.ecolind.2018.01.010

Souplet A. 1996. Calculation of abundance indices and length frequencies in the MEDITS survey. In: Bertrand J.A. et al. (eds), Campagne internationale du chalutage démersal en Méditerraneé. Campagne 1995. EU Final Report, Vol. III.

Spedicato M.T., Bitetto I., Carbonara P., et al. 2014. Methodological support for exploring the LFI: "proportion of large fish - indicator" properties for interpreting the changes in the fish community of the South Adriatic area (GSA18). In: First MedSuit Regional Workshop on indicators and targets to ensure GES of commercially exploited marine populations in the GFCM area. FAO HQs, Rome, Italy, 6-7 November 2014

Spedicato M.T., Massutí E., Merigot B., et al. 2019. The MEDITS 
trawl survey specifications in an ecosystem approach to fishery management. Sci. Mar. 83S1: 9-20.

https://doi.org/10.3989/scimar.04915.11X

Vasilakopoulos P., Raitsos D.E., Tzanatos E. 2017. Resilience and regime shifts in a marine biodiversity hotspot. Sci. Rep. 7: 13647.

https://doi.org/10.1038/s41598-017-13852-9

Winemiller K.O., Rose K.A. 1992. Patterns of life-history diversification in North American fishes: implications for population regulation. Can. J. Fish. Aquat. Sci. 49: 2196-2218. https://doi.org/10.1139/f92-242

Yong A.G., Pearse S. 2013. A Beginner's Guide to Factor Analysis: Focusing on Exploratory Factor Analysis. TQMP 9: 79-94. https://doi.org/10.20982/tqmp.09.2.p079

Zuur A.F., Tuck I.D., Bailey N. 2003. Dynamic factor analysis to estimate common trends in fisheries time series. Can. J. Fish. Aquat. Sci. 60: 542-552.

https://doi.org/10.1139/f03-030

\section{SUPPLEMENTARY MATERIAL}

The following supplementary material is available through the online version of this article and at the following link:

http://scimar.icm.csic.es/scimar/supplm/sm05015esm.pdf

Table S1. - List of the 23 species included in the analysis for the calculation of community indicators

Table S2. - Kaiser-Meyer-Olkin test: measure of sampling adequacy by GSA. In bold the KMO criterion values $<0.5$.

Table S3. - Lifespan by species used to estimate the average lifespan of the fish community considered.

Table S4. - Mean temperature of the catch, as found in Cheung et al. (2013), related to the species under investigation. For deepwater species (indicated by*), SST is not considered a reliable indicator of temperature preference.

Table S5. - Correlations (Pearson) among the indicators by GSAs. In bold, the significant correlations $(\mathrm{P}<0.05)$ are reported.

Table S6. - Trends of biomass $\left(\mathrm{kg} \mathrm{km}^{-2}\right)$ by GSA/species over the time series (1999-2015) represented. Species not considered in areas are indicated as NA.

Table S7. - Trends of abundance $\left(\mathrm{N} \mathrm{km}^{-2}\right)$ by GSA/species over the time series (1999-2015) represented. Species not considered in areas are indicated as NA.

Table S8. - Best models fitted by DFA for TyL and MML. The characteristics of the best models are described: the observation error covariance matrix $R$; the list of covariates included (none, one, two or up to three) and the Akaike information criteria corrected for small sample size (AICc), used to identify the best model for the indicators TyL and MML. The best model for both indicators, shown in bold font, has diagonal and equal matrix and no covariates.

Table S9. - Correlations between covariates. The significant correlations $(\mathrm{p}<0.05)$ are indicated in bold

Fig. S1. - Residuals histograms of the best DFA fit for TyL and MML broken down by normal mixed distributions through a scale mixture model.

Fig. S2 - TyL time series by GSA.

Fig. S3. - MML time series by GSA.

Fig. S4. - Trend in biomass $\left(\mathrm{kg} \mathrm{km}^{-2}\right)$ by species. The index is related to GSAs $1,7,8,9,10,11,15,16$ and 25 .

Fig. S5. - Trend in abundance $\left(\mathrm{N} \mathrm{km}^{-2}\right)$ by species. The index is related to GSAs 5, 6, 7, 8, 9, 11, 17, 18 and 19 .

Fig. S6. - Fitting of the best model selected by DFA for TyL. The blue lines represent TyL time series for each GSA. The smoothed black line represents the common trend for TyL.

Fig. S7. - Fitting of the best model selected by DFA for MML. The blue lines represent MML time series for each GSA. The smoothed black line represents the common trend for MML.

Fig. S8. - Correlation between the four covariates used in the analysis: fleet capacity (GTxKwxN of vessels), NAO, Med anomaly and SST $\left({ }^{\circ} \mathrm{C}\right)$. Correlation values are reported for each plot.

Fig. S9. - Temporal patterns of the four covariates used in the analysis: fleet capacity (GT x Kw x number of vessels), NAO, Med anomaly and $\operatorname{SST}\left({ }^{\circ} \mathrm{C}\right)$. 
Scientia Marina 83S1

December 2019, S1-S14, Barcelona (Spain)

ISSN-L: 0214-8358

\section{Modelling spatio-temporal patterns of fish community size structure across the northern Mediterranean Sea: an analysis combining MEDITS survey data, environmental and anthropogenic drivers}

Isabella Bitetto, Giovanni Romagnoni, Angeliki Adamidou, Gregoire Certain, Manfredi Di Lorenzo, Marilena Donnaloia, Giuseppe Lembo, Porzia Maiorano, Giacomo Milisenda, Claudia Musumeci, Francesc Ordines, Paola Pesci, Panagiota Peristeraki, Ana Pesic, Paolo Sartor, Maria Teresa Spedicato

Supplementary material 
Table S1. - List of the 23 species included in the analysis for the calculation of community indicators.

\begin{tabular}{llll}
\hline Medits code & Latin name & Medits code & Latin name \\
\hline ASPICUC & Chelidonichthys cuculus & PAGEBOG & Pagellus bogaraveo \\
CITHMAC & Citharus linguatula & PAGEERY & Pagellus erythrinus \\
EUTRGUR & Eutrigla gurnardus & PHYIBLE & Phycis blennoides \\
GALUMEL & Galeus melastomus & RAJACLA & Scyliorhinus canicula \\
HELIDAC & Helicolenus dactylopterus & SCYOCAN & Solea vulgaris \\
LEPMBOS & Lepidorhombus boscii & SOLEVUL & Spicara flexuosa \\
LOPHBUD & Lophius budegassa & SPICFLE & Spicara smaris \\
LOPHPIS & Lophius piscatorius & SPICSMA & Trigloporus lastoviza \\
MERLMER & Merluccius merluccius & TRIPLAS & Trisopterus capelanus \\
MULLBAR & Mullus barbatus & TRISCAP & Zeus faber \\
MULLSUR & Mullus surmuletus & ZEUSFAB & \\
PAGEACA & Pagellus acarne & & \\
\hline
\end{tabular}

\section{Adequacy of data to the analysis}

According to Kaiser-Meyer-Olkin test, the available data were considered relatively adequate to the analysis (Table S2). Globally, GSAs 2, 17 and 22+23 showed the lowest KMO-Criterion, indicating widespread variance that could be scarcely interpreted as common variability. For all the GSAs the Bartlett test returned a $p<0.05$, thus we always rejected the null hypothesis that the correlation matrix was equal to the identity matrix. The results of the tests carried out ensure the validity of the hypothesis of the PCA allowing to perform the analysis on the available data.

Table S2. - Kaiser-Meyer-Olkin test: Measure of sampling Adequacy (MSA) by GSA. In bold the KMO-Criterion values <0.5.

\begin{tabular}{|c|c|c|c|c|c|c|c|}
\hline \multirow[b]{2}{*}{ Kaiser-Meyer-Olkin } & \multicolumn{6}{|c|}{ Measure of sampling Adequacy (MSA) } & \multirow[b]{2}{*}{ KMO-Criterion } \\
\hline & LFI & Evennes.index & LSI & MML & MW & Typical_Length & \\
\hline GSA 1 & 0.76 & 0.22 & 0.69 & 0.80 & 0.43 & 0.59 & 0.60 \\
\hline GSA 2 & 0.40 & 0.44 & 0.43 & 0.33 & 0.59 & 0.19 & 0.41 \\
\hline GSA 5 & 0.66 & 0.70 & 0.75 & 0.60 & 0.72 & 0.68 & 0.68 \\
\hline GSA 6 & 0.70 & 0.69 & 0.55 & 0.28 & 0.60 & 0.70 & 0.63 \\
\hline GSA 7 & 0.50 & 0.53 & 0.27 & 0.52 & 0.62 & 0.57 & 0.53 \\
\hline GSA 8 & 0.61 & 0.16 & 0.57 & 0.36 & 0.62 & 0.77 & 0.56 \\
\hline GSA 9 & 0.51 & 0.56 & 0.79 & 0.41 & 0.78 & 0.57 & 0.57 \\
\hline GSA 10 & 0.60 & 0.55 & 0.61 & 0.56 & 0.49 & 0.57 & 0.57 \\
\hline GSA 11 & 0.55 & 0.84 & 0.46 & 0.44 & 0.52 & 0.59 & 0.56 \\
\hline GSA 15 & 0.68 & 0.74 & 0.79 & 0.56 & 0.72 & 0.76 & 0.72 \\
\hline GSA 16 & 0.60 & 0.57 & 0.74 & 0.63 & 0.56 & 0.65 & 0.63 \\
\hline GSA 17 & 0.45 & 0.31 & 0.45 & 0.41 & 0.53 & 0.47 & 0.44 \\
\hline GSA 18 & 0.40 & 0.82 & 0.77 & 0.76 & 0.82 & 0.70 & 0.74 \\
\hline GSA 19 & 0.81 & 0.90 & 0.64 & 0.62 & 0.51 & 0.68 & 0.69 \\
\hline GSA 20 & 0.56 & 0.75 & 0.54 & 0.60 & 0.62 & 0.58 & 0.60 \\
\hline GSA $22+23$ & 0.36 & 0.17 & 0.33 & 0.33 & 0.21 & 0.35 & 0.30 \\
\hline GSA 25 & 0.57 & 0.69 & 0.54 & 0.91 & 0.62 & 0.61 & 0.64 \\
\hline
\end{tabular}

\section{Average lifespan by species}

Table S3. - Lifespan by species used to estimate the average lifespan of the fish community considered.

\begin{tabular}{|c|c|c|c|}
\hline Species & Latin name & Lifespan & Reference \\
\hline ASPICUC & Chelidonichthys cuculus & 7 & Papaconstantinou 1983 \\
\hline CITHMAC & Citharus linguatula & 6 & Papacostantinou and Vassilopoulou 1994 \\
\hline EUTRGUR & Eutrigla gurnardus & 9 & Boudaya et al. 2008 \\
\hline GALUMEL & Galeus melastomus & 15 & http://www.marinetraining.eu/content/determination-age-and-growth- \\
\hline HELIDAC & Helicolenus dactylopterus & 10 & Romanelli et al. 1997 \\
\hline LEPMBOS & Lepidorhombus boscii & 9 & Landa and Fontenla 2016 \\
\hline LOPHBUD & Lophius budegassa & 21 & Landa et al. 2001 \\
\hline LOPHPIS & Lophius piscatorius & 24 & Landa et al. 2001 \\
\hline MERLMER & Merluccius merluccius & 20 & Muus et al. 1999 \\
\hline MULLBAR & Mullus barbatus & 10 & max age observed in GSAs 10,18 and 19 \\
\hline MULLSUR & Mullus surmuletus & 10 & Arslan and Ismen 2013 \\
\hline PAGEACA & Pagellus acarne & 12 & Velasco et al. 2011 \\
\hline PAGEBOG & Pagellus bogaraveo & 15 & Muus and Dahlstrom 1966 \\
\hline PAGEERY & Pagellus erythrinus & 12 & Livadas 1989 \\
\hline PHYIBLE & Phycis blennoides & 14 & Casas and Piñeiro 2000 \\
\hline RAJACLA & Raja clavata & 12 & Ryland and Ajayi 1984 \\
\hline SCYOCAN & Scyliorhinus canicula & 12 & Ivory et al. 2005 \\
\hline SOLEVUL & Solea vulgaris & 15 & Tmax Taylor on GSA10 and 18 DCF growth parameters \\
\hline SPICFLE & Spicara flexuosa & 5 & Mytilineou and Papaconstantinou 1991 \\
\hline SPICSMA & Spicara smaris & 5 & Soykan et al. 2010 \\
\hline TRIPLAS & Trigloporus lastoviza & 4 & El-serafy et al. 2015 \\
\hline TRISCAP & Trisopterus m. capelanus & 6 & Šantić et al. 2015 \\
\hline ZEUSFAB & Zeus faber & 12 & Maigret and Ly 1986 \\
\hline
\end{tabular}




\section{Temperature preference by species}

This section reports a table containing the available information of the temperature preference for the species under consideration. The mean temperature of the catch is obtained from Cheung et al. (2013), where available. For selected species, information from the online source Aquamaps (Kaschner et al. 2019; http://www.aquamaps.org) or from other sources was gathered.

The species with preference temperature higher than or equal to $17^{\circ} \mathrm{C}$ were considered thermophile.

Table S4. - Mean temperature of the catch, as found in Cheung et al. (2013), related to the species under investigation. For deep-water species (indicated by *), SST is not considered a reliable indicator of temperature preference.

\begin{tabular}{|c|c|c|c|}
\hline Species & MTC & Aquamaps & Other \\
\hline ASPICUC & - & & \\
\hline CITHMAC & 22 & & \\
\hline EUTRGUR & 11 & & \\
\hline GALUMEL* & 17 & 9-20; mean: 10.4 & 13.9-14.16; Ragonese et al. 2009 \\
\hline HELIDAC* & 22 & & \\
\hline LEPMBOS & 14 & & \\
\hline LOPHBUD* & 25 & & \\
\hline LOPHPIS* & 14 & & \\
\hline MERLMER & 18 & & \\
\hline MULLBAR & 17 & $17-20$ & \\
\hline MULLSUR & 19 & & \\
\hline PAGEACA & 19 & & \\
\hline PAGEBOG & 18 & & \\
\hline PAGEERY & 18 & 12.2-21; mean: 17.2 & \\
\hline PHYIBLE & 16 & & \\
\hline RAJACLA & 17 & & \\
\hline SCYOCAN & 17 & & \\
\hline SOLEVUL & 16 & & \\
\hline SPICFLE & - & & \\
\hline SPICSMA & - & 11.8-17.8; mean: 14.4 & \\
\hline TRIPLAS & 18 & & \\
\hline TRISCAP & 15 & & \\
\hline ZEUSFAB & 23 & & \\
\hline
\end{tabular}

\section{Normality of residuals in DFA}

The Shapiro-Wilk test detected deviations from normal distributions in the residuals of the DFA best fits for TyL and MML; this was investigated by scale finite mixture model. This analysis indicated that for TyL the $90 \%$ of residuals are represented by a normal distribution with mean -0.17 and standard deviation 0.69 , while the second normal component (10\% of residuals) is characterized by mean of 1.72 and standard deviation 0.77 . For MML the residuals are divided in $96 \%$ due to a normal distribution with mean -0.13 and standard deviation 0.81 and another normal distribution (4\% of residuals) with mean -1.82 and standard deviation 0.41 (Fig. S1).
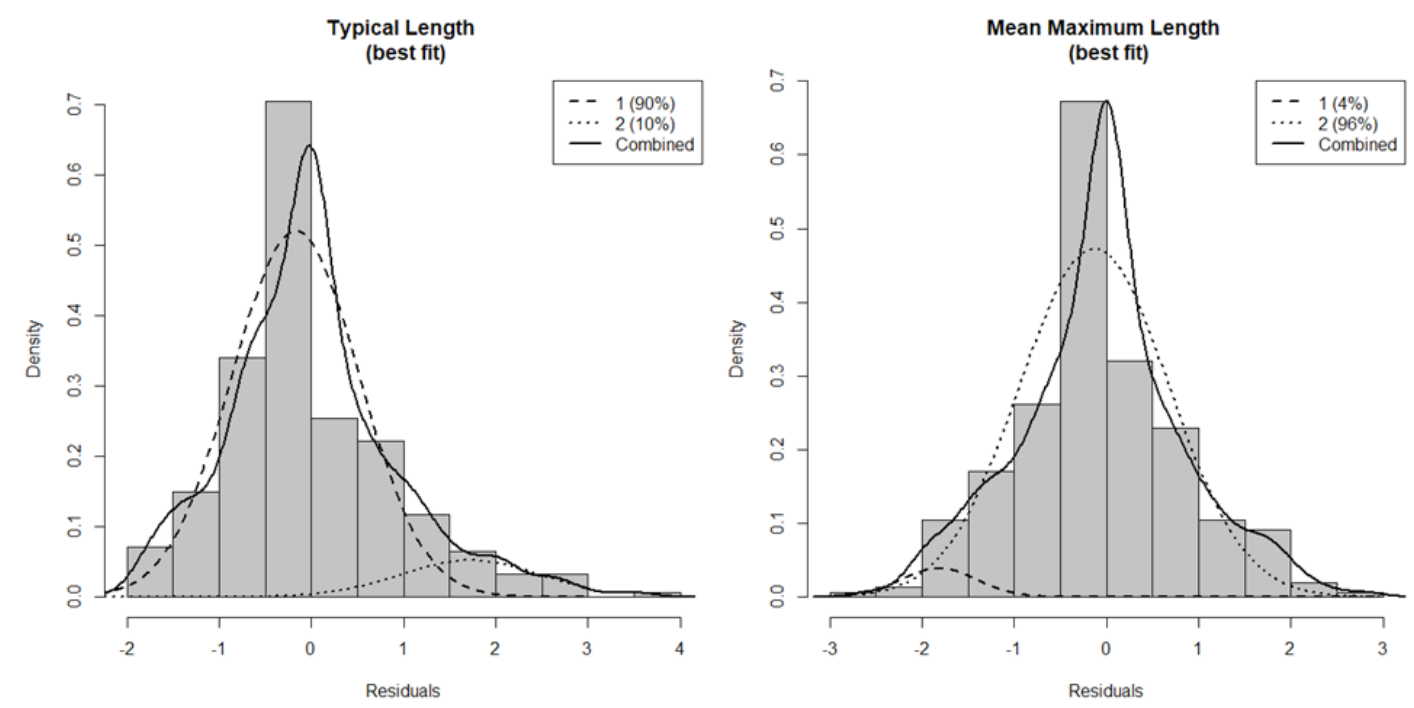

Fig. S1 - Residuals histograms of the best DFA fit for TyL and MML broken down by normal mixed distributions through scale mixture model. 


\section{Correlations among the indicators by GSAs}

Before carrying out the PCA, the hypotheses needed to apply any factor analysis were verified. The correlations among the six indicators for each GSAs were statistically tested using Pearson's coefficient and the results are reported in Table S4.

Table S5. - Correlations (Pearson) among the indicators by GSAs. In bold the significant correlations $(\mathrm{P}<0.05)$ are reported.

\begin{tabular}{|c|c|c|c|c|c|c|c|}
\hline & Indicator & LFI & Evenness & LSI45 & MML & MW & TyL \\
\hline \multirow{6}{*}{ GSA1 } & LFI & 1 & & & & & \\
\hline & Evenness & 0.31 & 1 & & & & \\
\hline & LSI45 & 0.98 & 0.35 & 1 & & & \\
\hline & MML & 0.85 & 0.34 & 0.9 & 1 & & \\
\hline & MW & 0.65 & 0.34 & 0.56 & 0.47 & 1 & \\
\hline & TyL & 0.98 & 0.25 & 0.95 & 0.82 & 0.74 & 1 \\
\hline \multirow{7}{*}{ GSA2 } & & LFI & Evenness & LSI45 & MML & MW & TyL \\
\hline & LFI & 1 & & & & & \\
\hline & Evenness & -0.37 & 1 & & & & \\
\hline & LSI45 & 0.88 & -0.51 & 1 & & & \\
\hline & MML & 0.54 & -0.16 & 0.77 & 1 & & \\
\hline & MW & -0.53 & 0.71 & -0.75 & -0.54 & 1 & \\
\hline & TyL & 0.03 & 0.42 & -0.1 & -0.25 & 0.44 & 1 \\
\hline \multirow{7}{*}{ GSA5 } & & LFI & Evenness & LSI45 & MML & MW & TyL \\
\hline & LFI & 1 & & & & & \\
\hline & Evenness & 0.71 & 1 & & & & \\
\hline & LSI45 & 0.61 & 0.76 & 1 & & & \\
\hline & MML & 0.38 & 0.72 & 0.93 & 1 & & \\
\hline & MW & 0.9 & 0.8 & 0.72 & 0.54 & 1 & \\
\hline & TyL & 0.95 & 0.76 & 0.74 & 0.54 & 0.97 & 1 \\
\hline \multirow{7}{*}{ GSA6 } & & LFI & Evenness & LSI45 & MML & MW & TyL \\
\hline & LFI & 1 & & & & & \\
\hline & Evenness & 0.53 & 1 & & & & \\
\hline & LSI45 & 0.87 & 0.34 & 1 & & & \\
\hline & MML & 0.12 & -0.24 & 0.4 & 1 & & \\
\hline & MW & 0.67 & 0.94 & 0.43 & -0.14 & 1 & \\
\hline & TyL & 0.87 & 0.81 & 0.76 & 0.11 & 0.9 & 1 \\
\hline \multirow{7}{*}{ GSA7 } & & LFI & Evenness & LSI45 & MML & MW & TyL \\
\hline & LFI & 1 & & & & & \\
\hline & Evenness & 0.21 & 1 & & & & \\
\hline & LSI45 & -0.17 & -0.03 & 1 & & & \\
\hline & MML & -0.34 & -0.07 & 0.34 & 1 & & \\
\hline & MW & 0.47 & 0.89 & -0.13 & -0.3 & 1 & \\
\hline & TyL & 0.91 & 0.48 & -0.32 & -0.36 & 0.7 & 1 \\
\hline \multirow{7}{*}{ GSA8 } & & LFI & Evenness & LSI45 & MML & MW & TyL \\
\hline & LFI & 1 & & & & & \\
\hline & Evenness & -0.12 & 1 & & & & \\
\hline & LSI45 & 0.98 & 0.01 & 1 & & & \\
\hline & MML & 0.37 & 0.36 & 0.5 & 1 & & \\
\hline & MW & 0.73 & 0.35 & 0.74 & 0.43 & 1 & \\
\hline & TyL & 0.97 & -0.03 & 0.94 & 0.31 & 0.83 & 1 \\
\hline \multirow{7}{*}{ GSA9 } & & LFI & Evenness & LSI45 & MML & MW & TyL \\
\hline & LFI & 1 & & & & & \\
\hline & Evenness & 0.51 & 1 & & & & \\
\hline & LSI45 & 0.27 & -0.36 & 1 & & & \\
\hline & MML & -0.23 & -0.77 & 0.63 & 1 & & \\
\hline & MW & 0.71 & 0.88 & -0.08 & -0.47 & 1 & \\
\hline & TyL & 0.96 & 0.63 & 0.25 & -0.22 & 0.84 & 1 \\
\hline \multirow{7}{*}{ GSA10 } & & LFI & Evenness & LSI45 & MML & MW & TyL \\
\hline & LFI & 1 & & & & & \\
\hline & Evenness & 0.04 & 1 & & & & \\
\hline & LSI45 & 0.75 & -0.2 & 1 & & & \\
\hline & MML & 0.44 & -0.38 & 0.84 & 1 & & \\
\hline & MW & 0.34 & 0.72 & 0 & -0.2 & 1 & \\
\hline & TyL & 0.85 & 0.29 & 0.56 & 0.29 & 0.69 & 1 \\
\hline \multirow{7}{*}{ GSA11 } & & LFI & Evenness & LSI45 & MML & MW & TyL \\
\hline & LFI & 1 & & & & & \\
\hline & Evenness & 0.64 & 1 & & & & \\
\hline & LSI45 & 0.2 & 0.11 & 1 & & & \\
\hline & MML & -0.14 & 0.05 & 0.83 & 1 & & \\
\hline & MW & 0.45 & 0.64 & 0.11 & 0.14 & 1 & \\
\hline & TyL & 0.91 & 0.71 & 0.38 & 0.12 & 0.67 & 1 \\
\hline
\end{tabular}


Table S5 (Cont.). - Correlations (Pearson) among the indicators by GSAs. In bold the significant correlations $(\mathrm{P}<0.05)$ are reported.

\begin{tabular}{|c|c|c|c|c|c|c|c|}
\hline GSA15 & $\begin{array}{c}\text { LFI } \\
\text { Evenness } \\
\text { LSI45 } \\
\text { MML } \\
\text { MW } \\
\text { TyL }\end{array}$ & $\begin{array}{c}\text { LFI } \\
1 \\
0.94 \\
0.97 \\
0.61 \\
0.9 \\
0.98\end{array}$ & $\begin{array}{c}\text { Evenness } \\
1 \\
\mathbf{0 . 8 9} \\
\mathbf{0 . 6 2} \\
\mathbf{0 . 8 9} \\
\mathbf{0 . 9 3}\end{array}$ & $\begin{array}{l}1 \\
0.73 \\
0.86 \\
0.97\end{array}$ & $\begin{array}{c}1 \\
0.5 \\
\mathbf{0 . 6 6}\end{array}$ & $\begin{array}{c}1 \\
0.95 \\
\end{array}$ & TyL \\
\hline GSA16 & $\begin{array}{c}\text { LFI } \\
\text { Evenness } \\
\text { LSI45 } \\
\text { MML } \\
\text { MW } \\
\text { TyL }\end{array}$ & $\begin{array}{l}\text { LFI } \\
1 \\
0.02 \\
\mathbf{0 . 9 3} \\
0.47 \\
0.46 \\
\mathbf{0 . 9 2}\end{array}$ & $\begin{array}{c}1 \\
-0.15 \\
0.09 \\
\mathbf{0 . 8} \\
0.32\end{array}$ & $\begin{array}{l}1 \\
\mathbf{0 . 5 7} \\
0.29 \\
\mathbf{0 . 8 1}\end{array}$ & $\begin{array}{c}1 \\
0.35 \\
\mathbf{0 . 5 3}\end{array}$ & $\begin{array}{l} \\
1 \\
0.74\end{array}$ & TyL \\
\hline GSA17 & $\begin{array}{c}\text { LFI } \\
\text { Evenness } \\
\text { LSI45 } \\
\text { MML } \\
\text { MW } \\
\text { TyL }\end{array}$ & $\begin{array}{c}\text { LFI } \\
1 \\
0.33 \\
-0.09 \\
-0.4 \\
\mathbf{0 . 7 5} \\
\mathbf{0 . 8 9}\end{array}$ & $\begin{array}{c}\text { Evenness } \\
1 \\
\mathbf{0 . 5 6} \\
0.26 \\
0.23 \\
\mathbf{0 . 5 4}\end{array}$ & $\begin{array}{c}\text { LSI45 } \\
\\
\\
1 \\
\mathbf{0 . 9} \\
-0.28 \\
0.09\end{array}$ & $\begin{array}{c}1 \\
-0.51 \\
-0.22\end{array}$ & $\begin{array}{c}1 \\
0.86\end{array}$ & TyL \\
\hline GSA18 & $\begin{array}{c}\text { LFI } \\
\text { Evenness } \\
\text { LSI45 } \\
\text { MML } \\
\text { MW } \\
\text { TyL }\end{array}$ & $\begin{array}{c}\text { LFI } \\
1 \\
0.03 \\
0.26 \\
0.01 \\
0.34 \\
\mathbf{0 . 6 7}\end{array}$ & $\begin{array}{c}\text { Evenness } \\
1 \\
\mathbf{0 . 7 9} \\
\mathbf{0 . 8 1} \\
\mathbf{0 . 8 6} \\
\mathbf{0 . 6 9}\end{array}$ & $\begin{array}{c}1 \\
1 \\
0.9 \\
0.76 \\
0.76\end{array}$ & $\begin{array}{c} \\
1 \\
0.71 \\
0.6\end{array}$ & $\begin{array}{c}1 \\
0.87\end{array}$ & TyL \\
\hline GSA19 & $\begin{array}{c}\text { LFI } \\
\text { Evenness } \\
\text { LSI45 } \\
\text { MML } \\
\text { MW } \\
\text { TyL }\end{array}$ & $\begin{array}{c}\text { LFI } \\
1 \\
0.71 \\
0.87 \\
0.53 \\
0.5 \\
0.93\end{array}$ & $\begin{array}{c}\text { Evenness } \\
1 \\
1 \\
\mathbf{0 . 6 8} \\
\mathbf{0 . 6 2} \\
\mathbf{0 . 6 6} \\
\mathbf{0 . 8 2}\end{array}$ & $\begin{array}{c}\text { LSI45 } \\
\\
\\
1 \\
\mathbf{0 . 8} \\
0.35 \\
\mathbf{0 . 8 7}\end{array}$ & $\begin{array}{c}1 \\
0.35 \\
\mathbf{0 . 6 3}\end{array}$ & $\begin{array}{c}1 \\
\mathbf{0 . 6 9}\end{array}$ & TyL \\
\hline GSA20 & $\begin{array}{c}\text { LFI } \\
\text { Evenness } \\
\text { LSI45 } \\
\text { MML } \\
\text { MW } \\
\text { TyL }\end{array}$ & $\begin{array}{c}\text { LFI } \\
1 \\
-0.03 \\
0.12 \\
-0.33 \\
0.45 \\
\mathbf{0 . 7 9}\end{array}$ & $\begin{array}{c}\text { Evenness } \\
1 \\
0.54 \\
0.59 \\
0.54 \\
0.29\end{array}$ & $\begin{array}{c}1 \\
0.67 \\
0.21 \\
0.15\end{array}$ & $\begin{array}{c}1 \\
0.16 \\
-0.16\end{array}$ & $\begin{array}{c}1 \\
0.78\end{array}$ & TyL \\
\hline GSA22+23 & $\begin{array}{c}\text { LFI } \\
\text { Evenness } \\
\text { LSI45 } \\
\text { MML } \\
\text { MW } \\
\text { TyL }\end{array}$ & $\begin{array}{c}\text { LFI } \\
1 \\
-0.34 \\
\mathbf{0 . 8 8} \\
0.5 \\
-0.09 \\
\mathbf{0 . 9 4}\end{array}$ & $\begin{array}{c}\text { Evenness } \\
1 \\
-0.08 \\
0.34 \\
\mathbf{0 . 7 8} \\
-0.15\end{array}$ & $\begin{array}{c}1 \\
0.6 \\
0.05 \\
\mathbf{0 . 9}\end{array}$ & $\begin{array}{c}1 \\
0.71 \\
0.7\end{array}$ & $\begin{array}{c}1 \\
0.2\end{array}$ & TyL \\
\hline GSA25 & $\begin{array}{c}\text { LFI } \\
\text { Evenness } \\
\text { LSI45 } \\
\text { MML } \\
\text { MW } \\
\text { TyL }\end{array}$ & $\begin{array}{c}\text { LFI } \\
1 \\
0.78 \\
0.97 \\
0.91 \\
0.8 \\
0.95\end{array}$ & $\begin{array}{c}\text { Evenness } \\
1 \\
1 \\
\mathbf{0 . 6 5} \\
\mathbf{0 . 9} \\
\mathbf{0 . 8 9} \\
\mathbf{0 . 8 9}\end{array}$ & $\begin{array}{l}1 \\
0.85 \\
0.74 \\
0.88\end{array}$ & $\begin{array}{c}1 \\
0.97 \\
0.97\end{array}$ & $\begin{array}{c}1 \\
\mathbf{0 . 9 3}\end{array}$ & TyL \\
\hline
\end{tabular}




\section{Time series}

Figure S2 shows the trend of the TyL for each GSA; Figure S3 the MML by GSA. Figure S4 reports the biomass indices (summing up the different GSAs) by species related to the GSAs where an increasing trend was found in the Typical length (Fig. S2), namely in GSAs 1, 10, 11, 15, 16, 25, 6, 7, 8 and 9. This Figure highlights the species responsible of the trend in the TyL, focusing on the areas where a stronger relationship between the indicator and the biomass (which the definition of Typical length is based on) was found. Figure S5 shows the abundance (density) indices by species, summing up the GSAs where a decreasing trend in the MML was observed (Fig. S3). Figure 5S has the aim to highlight the species responsible of the trend in the MML, focusing on the areas where a stronger relationship between the indicator and the density (which the definition of MML is based on) was found.

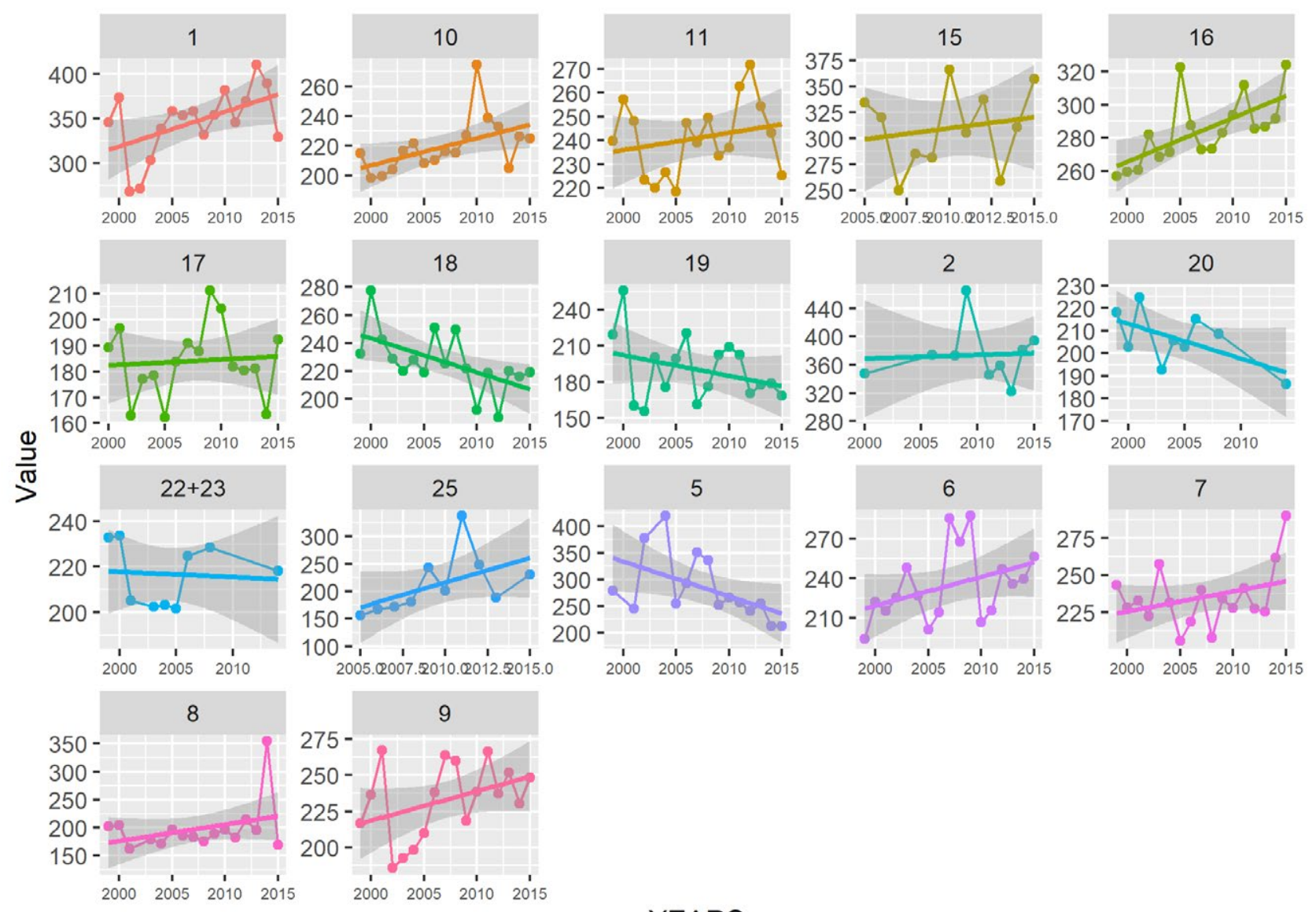

\section{YEARS}

Fig. S2. - TyL time series by GSA. 


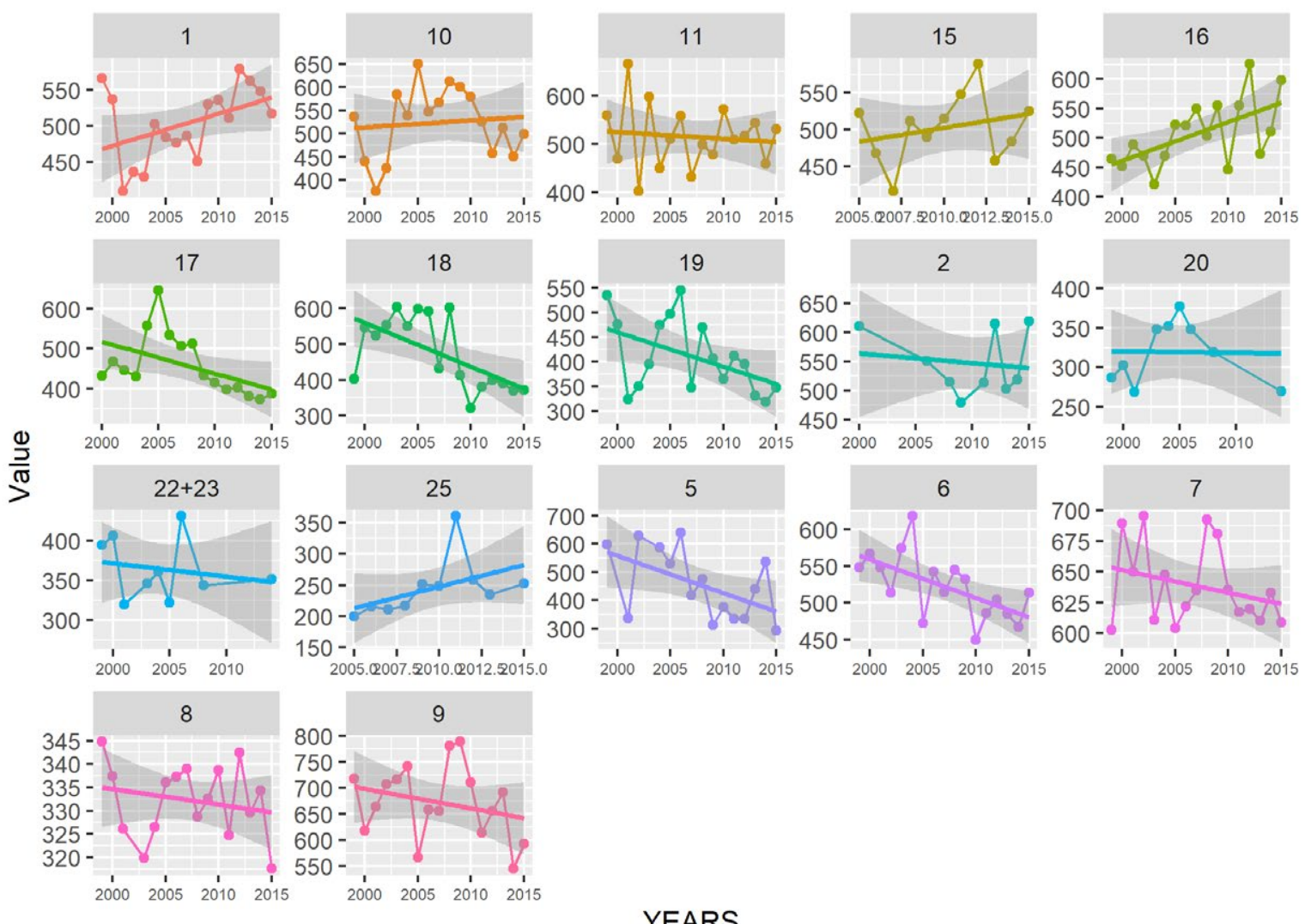

Fig. S3. - MML time series by GSA.
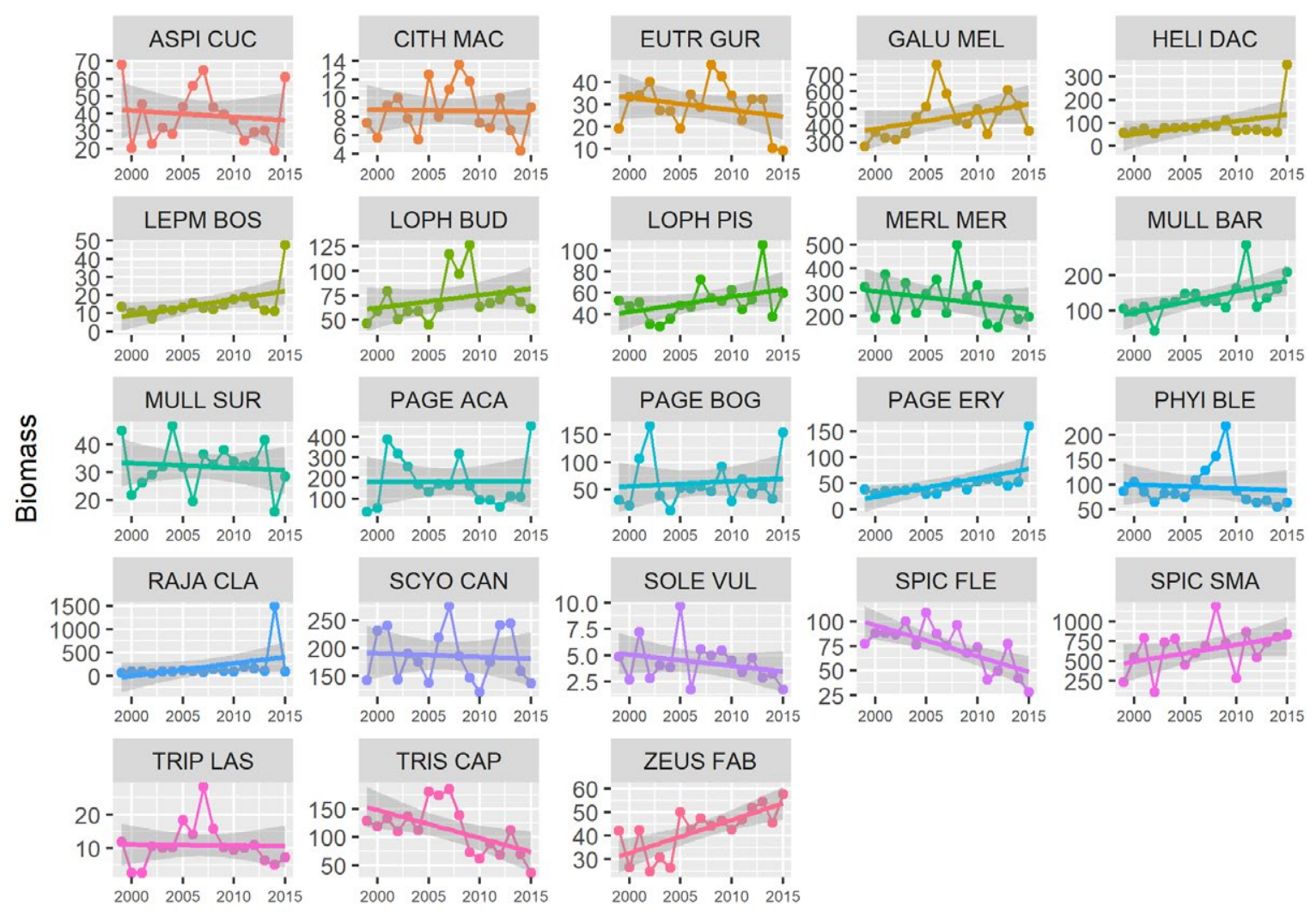

Anno

Fig. S4. - Trend in biomass $\left(\mathrm{kg} \mathrm{km}^{-2}\right)$ by species. The index is related to GSAs 1, 7, 8, 9, 10, 11, 15, 16 and 25. 


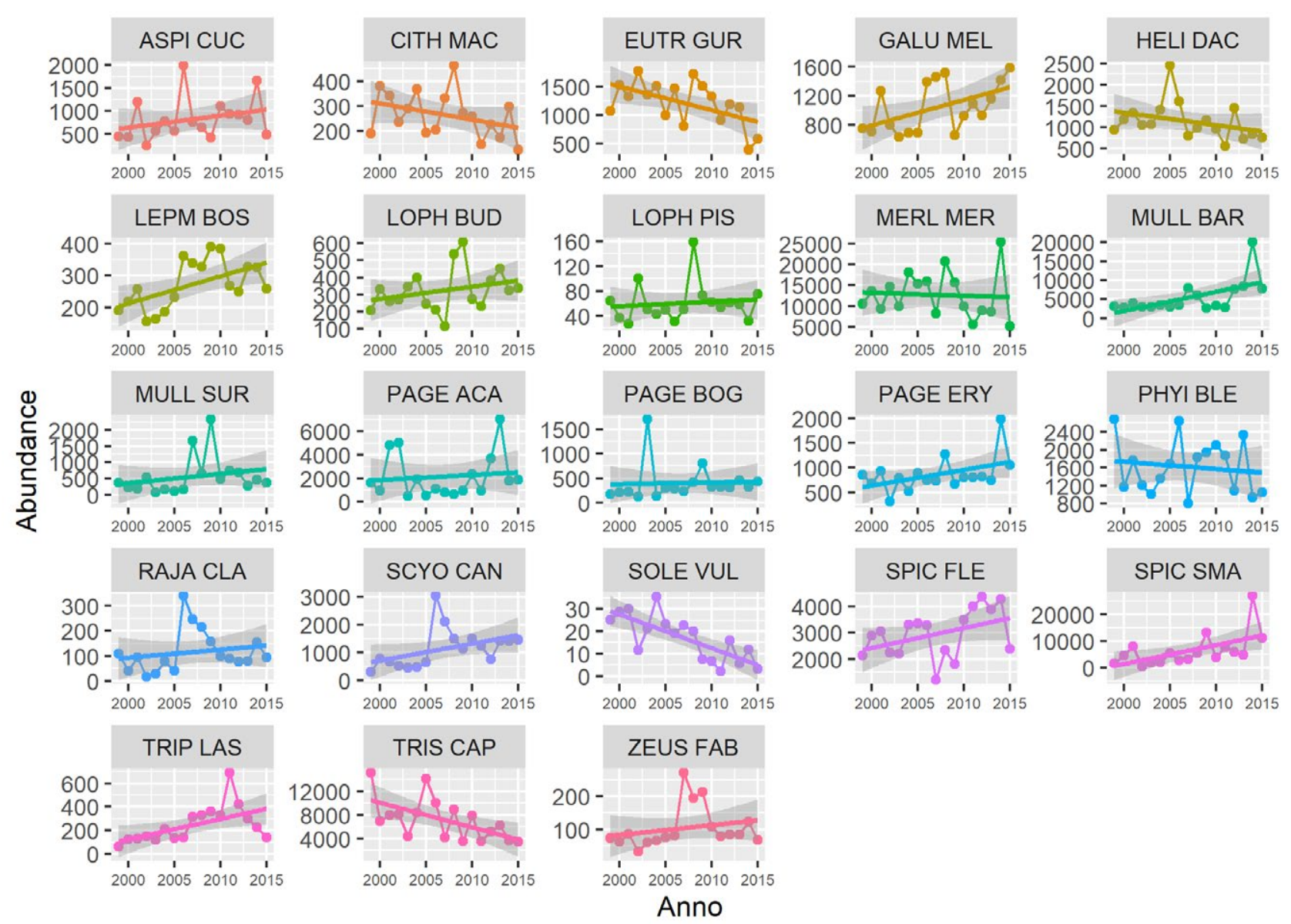

Fig. S5. - Trend in abundance $\left(\mathrm{N} \mathrm{km}^{-2}\right)$ by species. The index is related to GSAs 5, 6, 7, 8, 9, 11, 17, 18, 19.

\section{Trends by GSA/species}

In this section the trends of biomass and abundance indices per species and GSA are reported. 


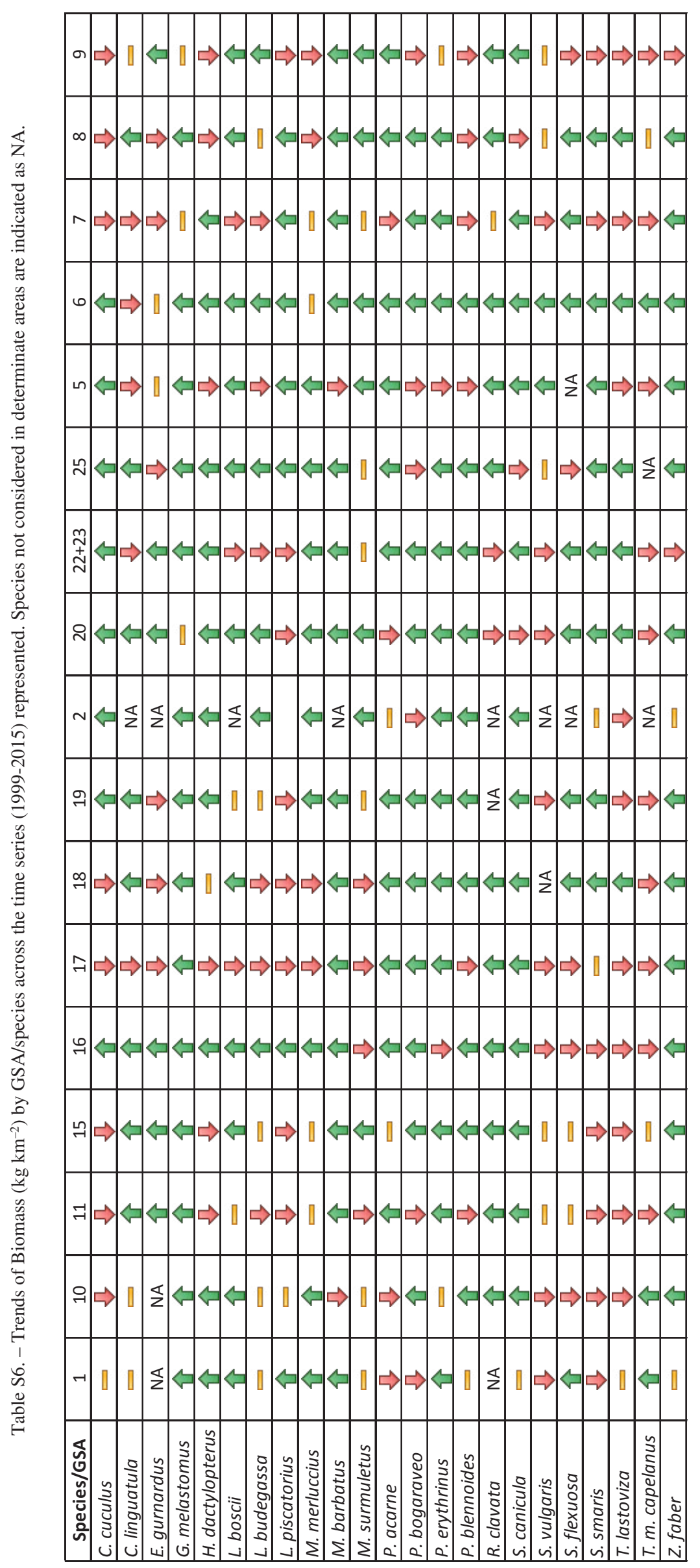


S10 - I. Bitetto et al.

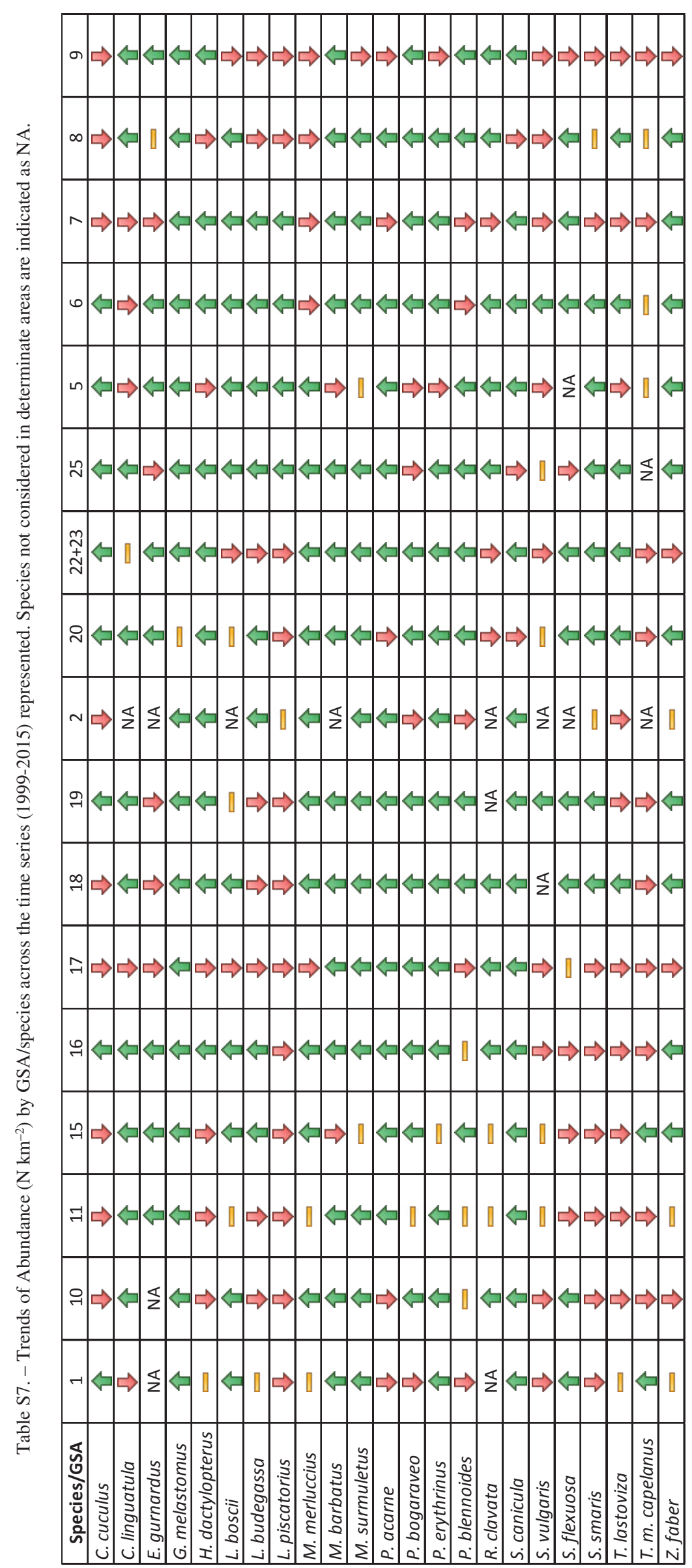




\section{Model fits by DFA}

Table S8. - Best models fitted by DFA for TyL and MML. The characteristics of the best models are described: the observation error covariance matrix $R$; the list of covariates included (none, one, two or up to three) and the Akaike Information Criteria corrected for small sample size (AICc), used to identify the best model for each of the indicators TyL and MML. The best model for both indicators, shown in bold font, has matrix diagonal and equal and no covariates.

\begin{tabular}{|c|c|c|c|}
\hline Obs. error cov. matrix $(R)$ & Covariates included & AICc TyL & AICc MML \\
\hline diagonal and equal & None & 690 & 675 \\
\hline diagonal and equal & $N A O$ & 706 & 701 \\
\hline diagonal and equal & MedAnomaly & 721 & - \\
\hline diagonal and equal & Fleet capacity & 728 & 714 \\
\hline diagonal and equal & SST & 730 & 716 \\
\hline diagonal and equal & NAO-MedAnomaly & 734 & 736 \\
\hline diagonal and equal & Fleet_cap-SST & 743 & 737 \\
\hline diagonal and equal & Fleet capacity $-N A O$ & 744 & 743 \\
\hline diagonal and equal & NAO-SST & 746 & 743 \\
\hline diagonal and equal & Fleet capacity-MedAnomaly & 748 & 746 \\
\hline diagonal and equal & NAO-SST-Fleet capacity & 763 & 766 \\
\hline diagonal and equal & NAO-MedAnomaly-Fleet capacity & 770 & - \\
\hline equalvarcov & MedAnomaly & - & 709 \\
\hline equalvarcov & NAO-MedAnomaly-Fleet capacity & - & 783 \\
\hline
\end{tabular}

The number of common trends detected $(\mathrm{M})$ is equal to 1 in all models selected.

\section{Fitting of best model selected by DFA}

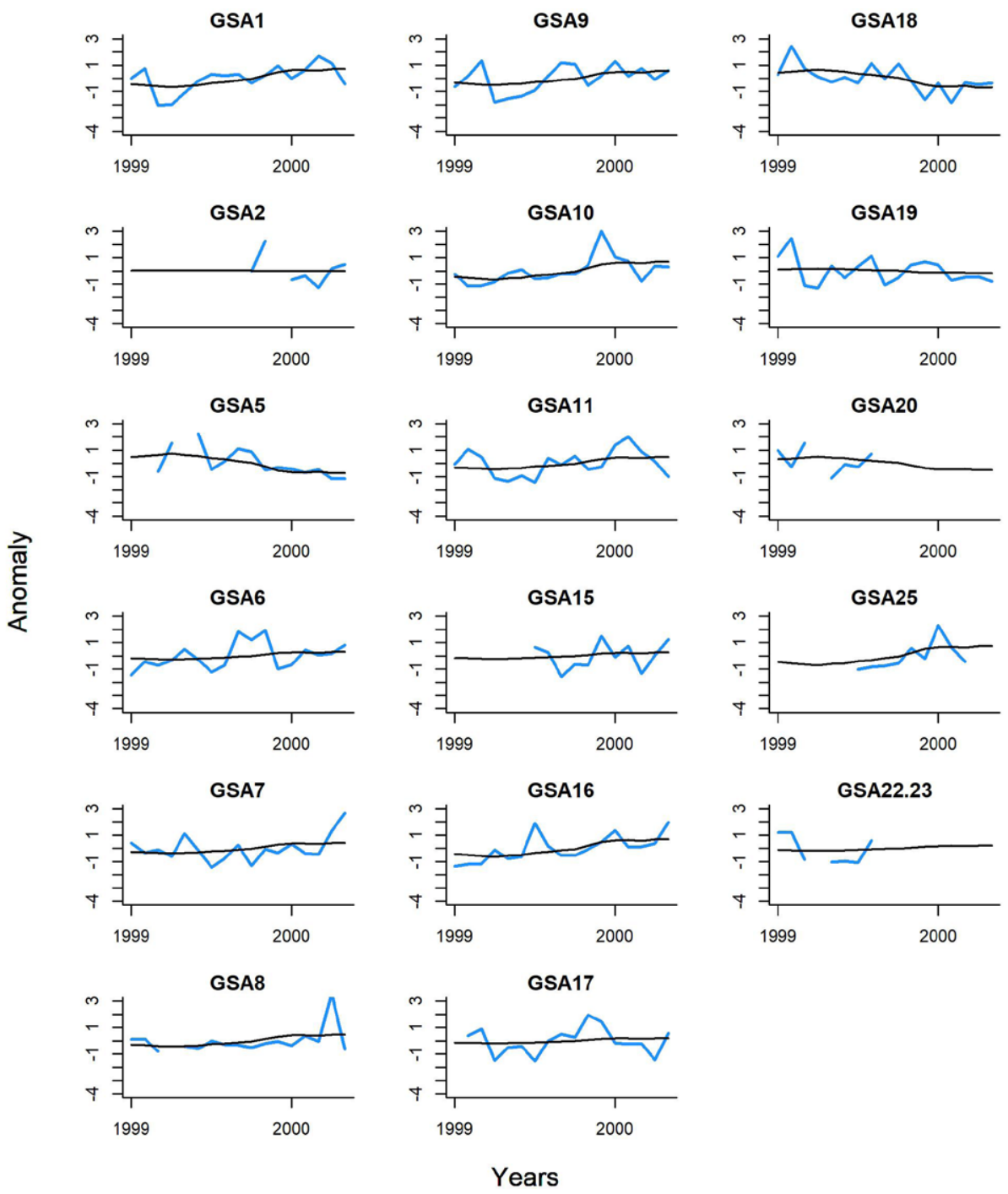

Fig. S6. - Fitting of the best model selected by DFA for TyL. The blue lines represent TyL time series for each GSA. The smoothed black line represents the common trend for TyL. 

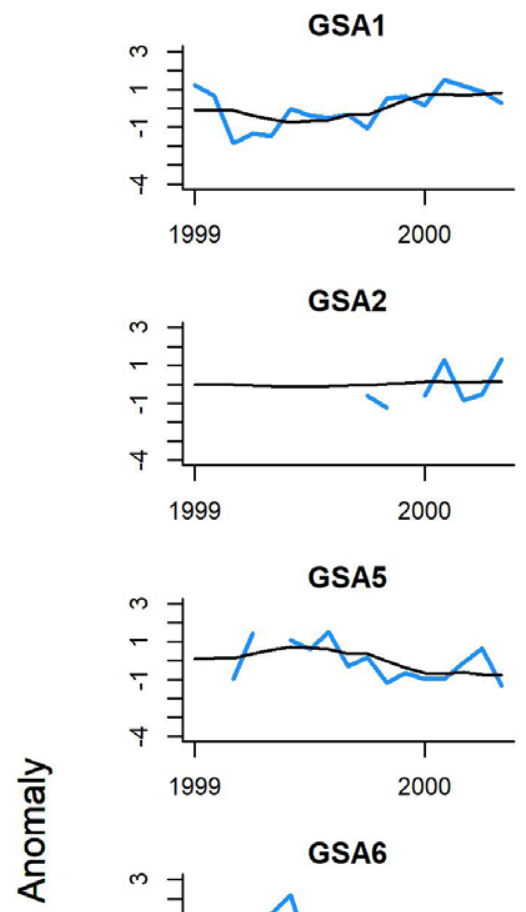

GSA6

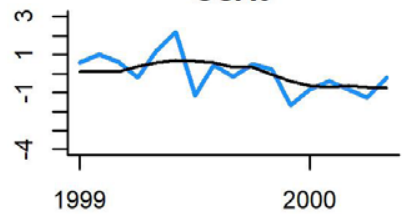

GSA7

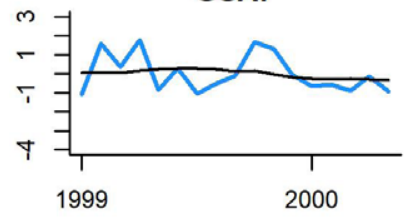

GSA8

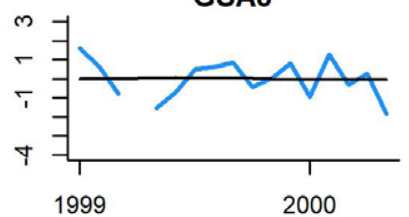

GSA9

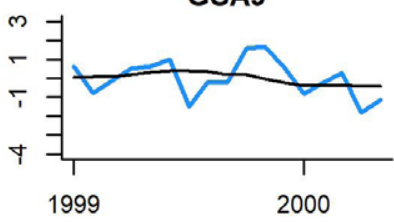

GSA10

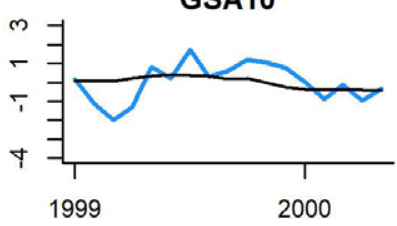

GSA11

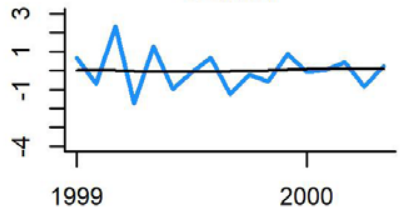

GSA15

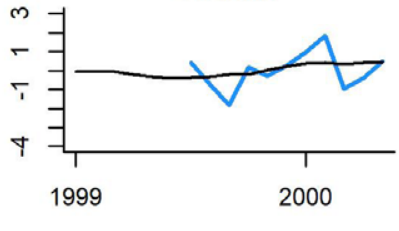

GSA16

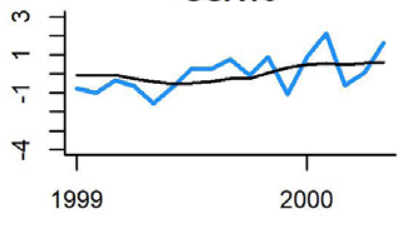

GSA17

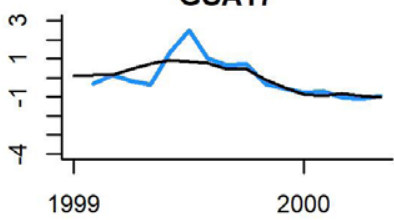

Years

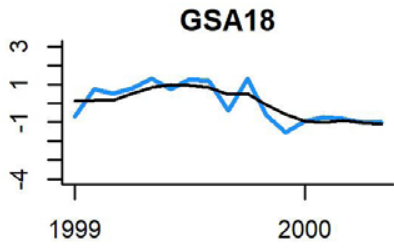

GSA19

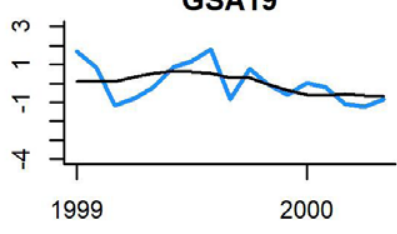

GSA20

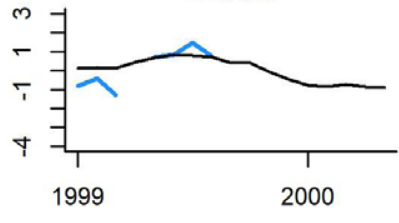

GSA25

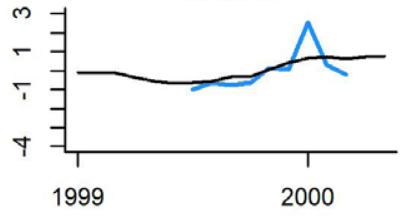

GSA22.23

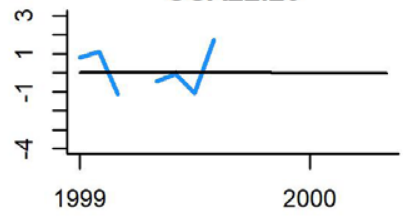

Fig. S7. - Fitting of the best model selected by DFA for MML. The blue lines represent MML time series for each GSA. The smoothed black line represents the common trend for MML.

\section{Covariates and correlations with trends}

Table S9. - Correlations between covariates. The significant $(\mathrm{p}<0.05)$ correlations are indicated in bold.

\begin{tabular}{lcccc}
\hline & Fleet capacity & MedAnomaly & NAO & SST \\
\hline Fleet capacity & 1 & $\mathbf{- 0 . 8 8}$ & -0.25 & $\mathbf{- 0 . 6 9}$ \\
MedAnomaly & $\mathbf{- 0 . 8 8}$ & 1 & 0.20 & $\mathbf{0 . 9 1}$ \\
NAO & -0.25 & 0.20 & 1 & 0.06 \\
SST & $\mathbf{- 0 . 6 9}$ & $\mathbf{0 . 9 1}$ & 0.06 & 1 \\
\hline
\end{tabular}



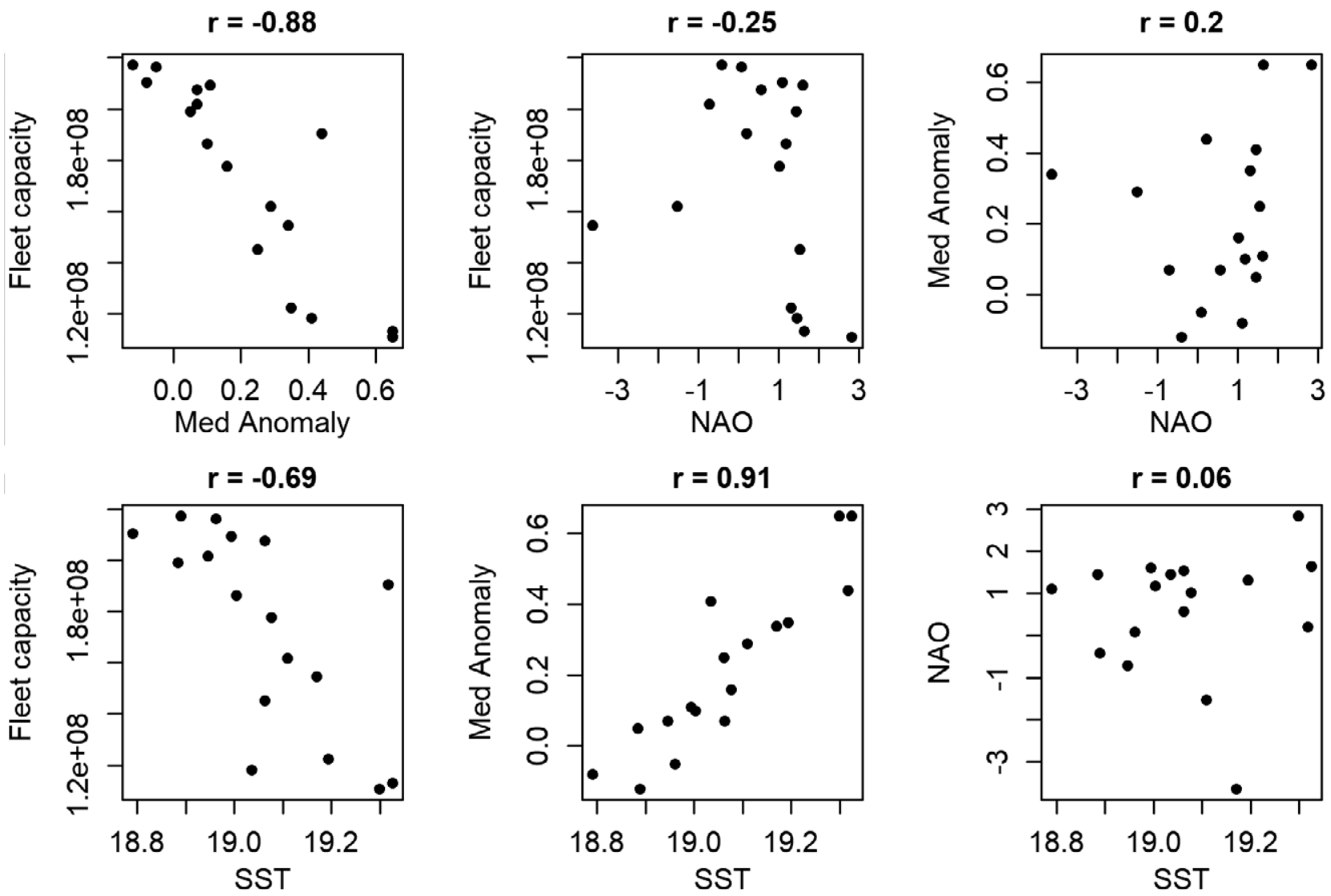

Fig. S8. - Correlation between the four covariates used in the analysis: Fleet capacity (GT $\times K w \times N$ of vessels), NAO, Med Anomaly and SST $\left({ }^{\circ} \mathrm{C}\right)$. Correlation values are reported for each plot.

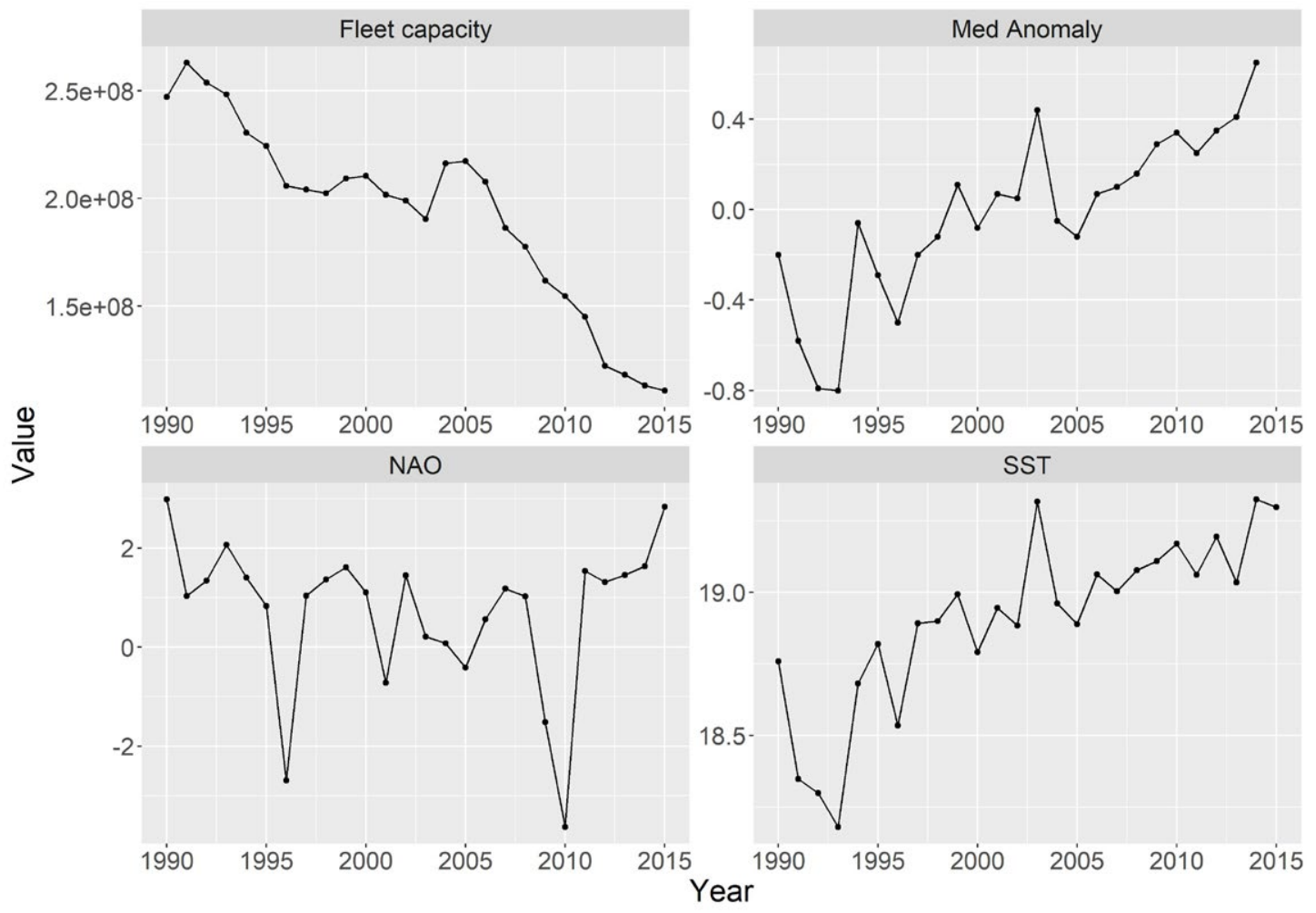

Fig. S9. - Temporal patterns of the four covariates used in the analysis: Fleet capacity (GT×Kw×number of vessels), NAO, Med Anomaly and SST $\left({ }^{\circ} \mathrm{C}\right)$. 


\section{REFERENCES}

Arslan M., Ismen A. 2013. Age, growth and reproduction of Mullus surmuletus (Linnaeus, 1758) in Saros Bay (Northern Aegean Sea). J. Black Sea/Medit. Environ. 19: 217-233.

Boudaya L., Neifar L., Rizzo P., et al. 2008. Growth and reproduction of Chelidonichthys lucerna (Linnaeus) (Pisces: Triglidae) in the Gulf of Gabès, Tunisia. J Appl Ichthyol. 24: 581-588. https://doi.org/10.1111/j.1439-0426.2008.01095.x

Casas J.M., Piñeiro C. 2000. Growth and age estimation of greater fork-beard (Phycis blennoides Brünich, 1768) in the north and northwest of the Iberian Peninsula (ICES Division VIIIc and IXa). Fish Res. 47: 19-25. https://doi.org/10.1016/S0165-7836(00)00108-9

Cheung W.W.L., Watson R., Pauly D. 2013. Signature of ocean warming in global fisheries catch. Nature, 497: 365-368. https://doi.org/10.1038/nature12156

El-Serafy S.S., El-Gammal F.I., Mehanna S.F., et al. 2015. Age growth and mortality of Streaked Gurnard (Trigloporus lastoviza, Bonnaterre, 1788) in the Egyptian Mediterranean waters off Alexandria. Int. J. Fish. Aquat. 3: 75-80.

Ivory P., Jeal F., Nolan C. P. 2005. Age Determination, Growth and Reproduction in the Lesser-spotted Dogfish, Scyliorhinus canicula (L .). J. Northwest Atl. Fish. Sci. 35: 89-106. https://doi.org/10.2960/J.v35.m504

Kaschner K., Kesner-Reyes K., Garilao C., et al. 2019. AquaMaps: predicted range maps for aquatic species. (Accessed 10 July 2019). http://www aquamaps.org

Landa J., Fontenla J. 2016. Age and growth of four spot megrim (Lepidorhombus boscii) in northern Iberian waters corroborated by cohort tracking. Estuar. Coast. Shelf Sci. 179: 181-188. https://doi.org/10.1016/j.ecss.2016.01.010

Landa J., Pereda P., Duarte R., et al. 2001. Growth of angler fish (Lophius piscatorius and L. budegassa) in Atlantic Iberian waters. Fish Res. 51: 363-376. https://doi.org/10.1016/S0165-7836(01)00260-0

Livadas R.J. 1989. A study of the biology and population dynamics of pandora (Pagellus erythrinus L., 1758), family Sparidae, in the seas of Cyprus. In: M. Savini and J.F. Caddy (eds), Report of the Second Technical Consultation on Stock Assessment in the Eastern Mediterranean, pp. 58-76. General Fisheries Council for the Mediterranean, Athens.
Maigret J., Ly B. 1986. Les poissons de mer de Mauritanie. Centre National de Recherches Océanographiques et des Pêches. Nouadhibou. $213 \mathrm{pp}$

Muus B. J., Dahlstrom P. 1966. Guide des poissons de mer et pêche. Neuchâtel, Delachaux \& Niestlé.

Muus B. J., Nielsen J. G., Dahlstrom P., et al. 1999. Sea fish. Scandinavian Fishing Year Book - Hedehusene. Narayana Press, Odder. 340 pp.

Mytilineou C., Papaconstantinou C. 1991. Age and growth of Spicara flexuosa (Raf. 1810) in the Patraikos Gulf (Greece). Sci. Mar. 55: 483-490.

Papaconstantinou C. 1983. Aspects on the biology of Aspitrigla cuculus (Pisces: Scorpaenifirmes) from the Saronikos Gulf. Thalassographica 6: 49-75.

Papacostantinou C., Vassilopoulou V. 1994. Age , growth and mortality of the spotted flounder (Citharus linguatula) in the Aegean Sea. Sci. Mar. 58: 261-267.

Ragonese S., Nardone G., Ottonello D., et al. 2009. Distribution and biology of the Blackmouth catshark Galeus melastomus in the Strait of Sicily (Central Mediterranean Sea). Mediterr. Mar. Sci. 10: $55-72$. https://doi.org/10.12681/mms.122

Romanelli M., Palladino S., Tarulli E., et al. 1997. Stima dell'accrescimento di Helicolenus d. dactylopetrus (Delaroche) in Adriatico Meridionale tramite esame dell sagittae di esemplari prelevati con reti a strascico e palangari di fondo. Biol. Mar. Mediterr. 4: 554-556.

Ryland J.S., Ajayi T.O. 1984. Growth and population dynamics of three Raja species (Batoidei) in Carmarthen Bay, British Isles. J. Cons. Int. Explor. Mer. 41: 111-120. https://doi.org/10.1093/icesjms/41.2.111

Šantić M., Pallaoro A., Mikulandra I., et al. 2015. Age, growth and mortality of poor cod (Trisopterus minutus L.) from the eastern Adriatic Sea. Arch. Biol. Sci. 67: 921-927. https://doi.org/10.2298/ABS141106053S

Soykan O., Ilkyaz A.T., Metin G., et al. 2010. Growth and reproduction of blotched picarel (Spicara maena Linnaeus, 1758) in the central Aegean Sea, Turkey. Turk. J. Zool. 34: 453-459.

Velasco E.M., Jimenez-Tenorio N., Del Arbol J., et al. 2011. Age, growth and reproduction of the axillary seabream, Pagellus acarne, in the Atlantic and Mediterranean waters off southern Spain. JMBAUK, 91: 1243-1253. https://doi.org/10.1017/S0025315410000305 